\title{
Biological/physical simulations of Calanus finmarchicus population dynamics in the Gulf of Maine
}

\author{
Daniel R. Lynch ${ }^{1, *}$, Wendy C. Gentleman ${ }^{1}$, Dennis J. McGillicuddy $\mathrm{Jr}^{2}{ }^{2}$ Cabell S. Davis ${ }^{2}$ \\ ${ }^{1}$ Dartmouth College. Hanover, New Hampshire 03755, USA \\ ${ }^{2}$ Woods Hole Oceanographic Institution, Woods Hole, Massachusetts 02543, USA
}

\begin{abstract}
A site-specific, coupled biological/physical model is described for the dominant winterspring copepod in the Gulf of Maine. The biological portion describes temperature- and fooddependent progression through 13 life stages in an Eulerian (concentration-based) framework. The population is transported in a flow field depicting the climatological mean conditions in 2 mo 'seasons'. Behavioural assumptions account for depth selection and 2 limiting cases are contrasted: dispersal throughout the water column, and aggregation in the surface layer. Simulations are inspired by MARMAP observations, with an emphasis on the mid-winter initiation of the annual bloom by diapausing populations, and their role in supplying reproducing populations to Georges Bank during spring. Passive tracer simulations illustrate the role of the circulation. Georges Bank itself is an open system and depends on resupply from external sources. All 3 deep basins of the Gulf are capable of contributing populations to the Bank. The Scotian Shelf is capable of populating the Southern Flank. In the case where the organisms aggregate in the surface layer, the effect of convergence in downwelling zones is shown to be a significant contributor to population distribution. Baseline population dynamics are initiated on January 1 by activating a diapausing population $\left(G_{0}\right)$ based on 10 yr mean abundance and distribution from the MARMAP program. The abundance and distribution of $G_{0}$ adults is reproduced with a 3-layer model, spatially variable mortality, an extended period of activation, no food limitation, and a large, heretofore unobserved source of diapausing C5s near-bottom. Reproduction modeled in this system shows significant development of generation $1\left(G_{1}\right)$ over the Gulf of Maine in February-March, which is not observed. Delay of reproduction over the Gulf, and/or severe early-stage mortality, is required to conform with the data. The space-time pattern of this effect is consistent with the observed chlorophyll distribution and timing, and reasonable food-limitation thresholds. Inclusion of this effect initiates the spring Calanus bloom in the correct space-time pattern, with significant cohorts of $G_{0}$ females and $G_{1}$ nauplii over important cod and haddock spawning grounds on Georges Bank. The implication is that $G_{1}$ is locally spawned in food-rich waters over Georges Bank by females advected in the food-poor Gulf of Maine surface layer.
\end{abstract}

KEY WORDS: Calanus S Simulation model · Gulf of Maine - Georges Bank

\section{INTRODUCTION}

Calanus finmarchicus (herein 'Calanus') is a dominant copepod in the Gulf of Maine (Fig. 1). The earliest investigations described the Gulf as a 'Calanus community' (Bigelow 1926), and subsequent investigations confirmed the stable importance of this species (Clark

·E-mail: d.r.lynch@dartmouth.edu et al. 1943, Mullin 1963, Davis 1987). More recent field programs continue to highlight the importance of Calanus in the Gulf. The 10 yr MARMAP program (Sherman et al. 1996) has refined our description of its year-round abundance and distribution, and the 2 yr SCOPEX program (Kenney \& Wishner 1995) has revealed important details of the interplay of biological and physical phenomena. Currently, Calanus is a key target species in the U.S. GLOBEC program which seeks to describe the biological and physical factors 


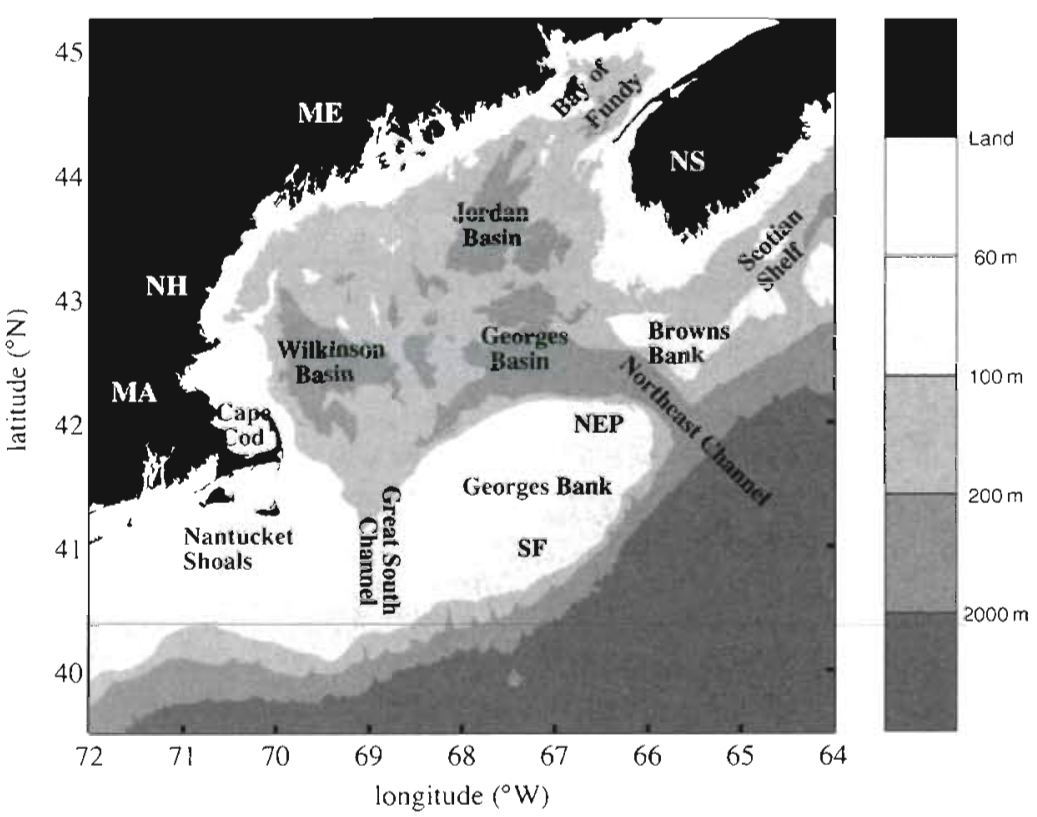

Fig. 1. The Gulf of Maine and Georges Bank. NEP: Northeast Peak; SF: Southern Flank

controlling its occurrence on Georges Bank (Davis 1991, GLOBEC 1991, 1992, Wiebe et al. 1996). Because Georges Bank is an open ecosystem, the investigation extends across the Gulf of Maine.

Our study is part of the GLOBEC effort. Current field sampling is dense from a practical standpoint ${ }^{1}$ but sparse compared to the space-time scales of planktonic organisms. Further, there is no routine sampling in the Gulf of Maine, and the smallest life stages representing at least half of an individual's development time are difficult to sample. Historical data are in general sparser (Davis 1987). Mathematical models are therefore a necessary companion to the field program. They are required to interpret the sparse measurements; to provide rigorous inference of the many unobservables which determine site-specific population dynamics; and to provide a framework for the assembly of a more complete quantitative description. We seek to model the abundance and distribution of Calanus toward these ends.

There is substantial knowledge with which to proceed. At various levels of precision, we know much about (1) the animal: beginning with Marshall \& Orr (1955) and continuing to the present (Hirche 1996a, b), there is an extensive literature describing Calanus reproduction and development, diapause, and response to environmental factors; (2) its broad patterns of abundance and distribution in the Gulf of Maine:

${ }^{1}$ U.S. GLOBEC broadscale surveys occupy 30 to 40 field stations sampled at 3 depths on Georges Bank, once a month. Each survey takes roughly $10 \mathrm{~d}$ to complete beginning with Bigelow (1926) and continuing through the subsequent field investigations described above; and (3) its physical setting: beginning with Bigelow (1927), and enhanced over the years by sustained efforts in the Gulf of Maine (e.g. Brooks 1985, Greenberg 1990, Brown \& Irish 1992) and Georges Bank (e.g. Flagg 1987).

As a result we have a qualitative life history of Calanus in the Gulf: resting stocks in diapause over summer and fall in the deep basins; activation in midwinter $_{i}$ transport to Georges Bank by the circulation; an on-bank bloom comprising 1 or 2 generations; return to diapause as the waters warm (Davis 1987). But this knowledge is incomplete, and the consistency of the 'story' is largely qualitative. The present study is the first attempt to put the existing information together in a quantitative, regional description.

A unique aspect of this work is the use of a sitespecific physical model with comprehensive coverage of the entire Gulf of Maine and reasonable resolution of Georges Bank (Lynch et al. 1996). This model provides climatological circulation patterns in 2 mo seasons which constitute the best available climatology for the system.

A second unique aspect is the recent publication of a 'Calanus climatology' in the form of $10 \mathrm{yr}$ seasonal mean abundance and distribution in 2 mo bins (Meise \& O'Reilly 1996). That study revealed a distinct seasonal cycle with low variance. We believe that this stable outcome can be described by the interaction of population dynamics, behaviour, and the mean physical cycle. Our study is founded on this premise.

We will focus on the initiation phase of the spring bloom, when deep resting populations are exiting diapause and producing a first generation cohort. Variability in this portion of the cycle will be greatly amplified in the second generation, so it is critical to understand this early phase.

\section{REVIEW OF PREVIOUS MODELING}

This is the first attempt to build a coupled biological/ physical model of Calanus for the Gulf of Maine. Several previous model studies have described Georges Bank in isolation. There are 2 families: ecosystem (NPZ) models which represent several trophic levels endogenously, and species-specific models. The former typically aggregate all zooplankton into a single variable; 
the latter permit detailed representation of the population structure for one species, at the expense of making the balance of the ecosystem exogenous. Most recently, we have seen the emergence of advanced Gulfwide circulation models and these have supported biologically inspired studies of passive tracers.

\section{Ecosystem models}

Klein (1987) described an NPZ model for Georges Bank, circulating in an idealized steady gyre. The study emphasized the roles of retention, loss, and in situ productivity during the spring bloom. The anomalously low secondary productivity observed on the Bank was a special focus. A basic outcome was the requirement for a 'phytoplankton detritus' variable in order to reproduce the observed bloom.

Lewis et al. (1994) studied the washout effect of wind events on the Bank. They used an advanced 3-D circulation model operating on an idealized geometry, without tides. A portion of this study examined NPZ dynamics; results supported the 'washout' hypothesis that strong wind events can produce significant loss of zooplankton from the bank.

Franks \& Chen (1996) examined the interaction of an NPZ model with detailed tidal dynamics on a 2-D, northsouth transect across Georges Bank. The results illuminate the cross-frontal processes at work on the dynamically different northern and southern flanks of the bank, and the formation of patches and gradients in the biological and chemical variables due to tidal processes.

\section{Species-specific models}

Davis (1984b) developed a species-specific model for Pseudocalanus spp. incorporating 13 life stages in an idealized steady gyre. In this and related studies of Calanus and Paracalanus parvus, he found that the interaction of population dynamics with the timing of the mean recirculation explained observed patterns of abundance and distribution; that food limitation was not operative on the bank; and that mortality from predators was likely to be the dominant control on abundance. This study demonstrated clearly the value of organismspecific models in a site-specific circulation regime.

Lewis et al. (1994) used a 4 -stage model of Pseudocalanus spp. to investigate the role of wind variability, using the advanced 3-D physical model described above. Conclusions were generally the same as from the NPZ model-loss from wind events can be ecologically significant-although details of the modeled response were different. The authors encourage a joint approach utilizing both system descriptions concurrently.
Flierl \& Davis (1997) demonstrated the reduction of complexity in an age- and stage-based model of Calanus, again in an idealized circulation regime. Keeping track of age within stage without artificial dispersion across stages required up to 200 state variables; use of empirical orthogonal functions allowed reduction to 10 to 20 state variables without loss of detail.

\section{Passive tracers}

Lewis (1997) extended the examiniation of the Georges Bank washout hypothesis by using passive tracers in a realistic 3-D Gulf-wide model forced by tides and observed wind timeseries. Results confirm that extreme winds are capable of interrupting the mean circulation and creating significant off-bank transport. Three individual winters were examined. In 2 of the 3 years, the mean circulation was largely undisturbed by the time-variable wind; but in the year with the largest and most variable wind, there was significant departure from the mean tendency.

Hannah et al. (1998) studied the transport of passive and vertically active particles released in the Gulf of Maine, using the same 3-D flow fields which we employ. They described the circulation as a seasonally varying 2-layer system with strong coupling between the Gulf and Georges Bank. The faster surface layer provided a conveyor belt to the Bank with biologically important transit times; the deeper circulation was more retentive. Animals moving from deep water to the surface in climatologically synchronized behavioural patterns could thus be expected to arrive on Georges Bank in space-time patterns consistent with the general Gulf of Maine Calanus story.

\section{The present study}

Our study follows in the species-specific tradition established by Davis (1984b). We couple a stage-based description of a single organism to the mean climatological circulation. Our scope is Gulf-wide, using the best model-generated physical description available. We explore the inference of the operative biological/ physical processes by seeking correspondence with a comprehensive set of observations constituting a 'climatology' for Calanus abundance and distribution.

\section{COUPLED BIOLOGICAL/PHYSICAL MODEL}

We use a stage-based model in a site-specific Eulerian framework. Concentration (number of organisms 
per $\mathrm{m}^{3}$ ) within each stage evolves due to physical transport, biological behaviour, and population dynamics.

\section{Circulation}

We use the finite element hydrodynamic model of Lynch et al. (1996). This is a nonlinear 3-D model which transports momentum, heat and salt in tidal time. Vertical mixing is represented by a level 2.5 turbulence closure scheme; horizontal mixing is represented by a mesh-and shear-dependent eddy viscosity. The domain of computation includes the Gulf of Maine, Georges Bank, and the Scotian Shelf.

A bimonthly climatology has been developed with this model and is displayed in Lynch et al. (1997). For practical purposes it is the same as that used by Naimie (1995) wherein the Georges Bank features are examined in detail. It incorporates an extensive hydrographic database from which the climatological seasons were initialized. These circulation fields and their diagnostic predecessors (Naimie et al. 1994) have been used in several studies of Lagrangian drift focused on larval cod and haddock on Georges Bank (Werner et al. 1993, Lough et al. 1994). Hannah et al. (1997) recently examined their implications for near-surface transport in the Gulf, a precursor to this study. Model verification has been examined relative to observed velocities (Naimie et al. 1994, Naimie 1995) and turbulence (Horne et al. 1995). Lynch et al. (1995) explored convergence relative to the numerical discretization.

These fields are archived in terms of tidal (M2) and Eulerian residual components, for 6 bimonthly realizations. For long-term simulations we have processed them as in Dortch et al. (1992) in order to remove the tidal variation but preserve its effect on the longterm Lagrangian transport. The Lagrangian mean velocity $\mathbf{V}_{\mathrm{L}}$ is approximated as the sum of the Eulerian mean $V_{E}$ plus a first-order correction $V_{S}$ (the Stokes velocity):

$$
V_{L}=V_{E}+V_{S}=V_{E}+\nabla \times B
$$

with the vector potential $\mathbf{B}$ accounting for the subtidal effect of $M 2$ tidal variations:

$$
\begin{aligned}
& B_{x}=\frac{1}{P} \int_{t_{0}}^{t_{0}+P}\left(V_{M 2} \int_{t_{0}}^{t} w_{M 2} \mathrm{~d} t^{\prime}\right) \mathrm{d} t=\frac{V W \sin \left(\phi_{v}-\phi_{w}\right)}{2 \omega} \\
& B_{Y}=\frac{1}{P} \int_{t_{0}}^{t_{0}+P}\left(W_{M 2} \int_{t_{0}}^{t^{2}} u_{M 2} \mathrm{~d} t^{\prime}\right) \mathrm{d} t=\frac{W U \sin \left(\phi_{w}-\phi_{u}\right)}{2 \omega} \\
& B_{z}=\frac{1}{P} \int_{t_{0}}^{t_{0}+P}\left(u_{M 2} \int_{t_{0}}^{t} V_{M 2} \mathrm{~d} t^{\prime}\right) \mathrm{d} t=\frac{U V \sin \left(\phi_{u}-\phi_{V}\right)}{2 \omega}
\end{aligned}
$$

where $(U, V, W)$ and $\left(\phi_{u}, \phi_{v}, \phi_{w}\right)$ are the amplitude and phases of the $M 2$ velocity; and $P=\frac{2 \pi}{\omega}$ is the period.
Tests of long-term trajectories using $V_{L}$ showed essential agreement, for present purposes, with trajectories obtained with full, detailed tidal resolution. In addition to the Lagrangian velocity fields, we utilize the time-mean of the modeled temperature and hydrodynamic mixing coefficients. The latter are largely generated by the tidal motion and are relatively constant over the period of interest. (Spatial variations are more important.) Temperature is in the range 5 to $10^{\circ} \mathrm{C}$ on Georges Bank and colder in the Gulf. It decreases monotonically during the period of interest, generally reaching a minimum in March.

\section{Transport}

Transport in these circulation fields is represented by the advective-diffusive-reactive equation:

$$
\frac{\partial C_{i}}{\partial t}+\nabla \cdot\left[\left(\mathbf{V}_{L}+\mathbf{V}_{b}\right) C_{1}-\mathbf{K} \nabla C_{i}\right]=R_{i}
$$

where $C_{1}(x, y, z, t)$ is the concentration of stage $i$ individuals (no. $\left.\mathrm{m}^{-3}\right), \mathbf{V}_{\mathrm{L}}(x, y, z, t)$ is the Lagrangian fluid velocity described above, $\mathbf{V}_{b}(x, y, z, t)$ is the mean swimming speed for stage $i, \mathbf{K}$ is the time-averaged hydrodynamic dispersion tensor, and $R_{j}(x, y, z, t)$ is the net source of stage $i$ individuals (no. $\mathrm{m}^{-3} \mathrm{~d}^{-1}$ ).

The term $V_{b} C_{1}$ represents behaviour-swimming and/or buoyancy effects. We assume that the horizontal effect is negligible. But the vertical effect is critical. For Calanus, we have essentially no systematic information about younger life stages in the field, either in terms of behaviour or typical depth distribution. For the later stages, reasonable swimming speeds of 1 body length $\mathrm{s}^{-1}$ would allow perfect depth regulation, even in the presence of the strong vertical mixing on Georges Bank. Hence the behavioural portion of the vertical transport dominates. We have very limited description of these behavioural details. But 2 behavioural extremes are informative and relevant; both result in simple 2-D vertically averaged descriptions.

In the first extreme, we assume the organisms are uniformly distributed over the entire water column. In that case the depth-averaged transport equations apply:

$$
H \frac{\partial \bar{C}_{i}}{\partial t}+\nabla \cdot\left(H \overline{\mathbf{V}}_{\mathrm{L}} \bar{C}_{i}-H \overline{\mathbf{K}}_{x y} \nabla \bar{C}_{i}\right)=H \bar{R}_{i}
$$

where $H(x, y)$ is the total fluid depth and the overbar indicates a vertical average. Taking advantage of the continuity equation, $\nabla \cdot\left(H \overline{\mathbf{V}}_{\mathrm{L}}\right)=0$, this reduces to the conventional advective-diffusive form:

$$
\frac{\partial \bar{C}_{i}}{\partial t}+\mathrm{V}_{\mathrm{L}} \nabla \bar{C}_{i}-\frac{1}{H} \nabla \cdot H \overline{\mathbf{K}}_{x y} \nabla \bar{C}_{i}=\bar{R}_{i}
$$


In the second extreme, we assume the organisms aggregate in a defined surface layer with thickness $h$ herein $25 \mathrm{~m}$-irrespective of vertical fluid transports. Behaviour in this case completely overwhelms the vertical hydrodynamic transport (both advective and dispersive parts). In particular, upwelling or downwelling which would normally transport a passive tracer has no impact on the animal count in the layer.

In this case, the vertically integrated transport equation is identical to Eq. (4) replacing $H$ with $h .{ }^{2}$ However here we have $\nabla \cdot\left(h \overline{\mathbf{V}}_{\mathrm{L}}\right)=w_{\text {, the }}$ upwelling velocity at the bottom of the layer; so the analog of Eq. (5) retains the divergence term:

$$
\frac{\partial \bar{C}_{i}}{\partial t}+\overline{\mathbf{V}}_{\mathrm{L}} \nabla \bar{C}_{1}-\frac{1}{h} \nabla \cdot h \overline{\mathbf{K}}_{x y} \nabla \bar{C}_{1}=-\mathrm{D} \bar{C}_{i}+\bar{R}_{i}
$$

where $\mathrm{D}$ is the layer divergence:

$$
D=\frac{1}{h} \nabla h \overline{\mathbf{V}}_{L}=\frac{w}{h}
$$

Divergence (upwelling) has the effect of diluting the layer, while convergence (downwelling) concentrates the organisms. In the absence of diffusion, we have from Eq. (6) the evolution of a cohort along a horizontal streamline:

$$
\frac{\mathrm{d} \bar{C}_{j}}{\mathrm{~d} t}=-\mathrm{D} \bar{C}_{i}+\bar{R}_{1}
$$

and we obtain the possibility of exponential concentration of a population which is passive biologically but actively swimming in a convergent layer. Clearly, this is a first-order effect on the distributional pattern which could be mistaken for population dynamics. We find here that values of $D$ are of the order of $0.1 \mathrm{~d}^{-1}$ in certain critical areas of the Gulf; this is comparable to time scales in the population dynamics (e.g. stage durations). Diffusion will erode this effect, depending on the horizontai scale. For convergence zones of size $L \geq \sqrt{K_{x y} / D}$, convergence will still dominate (Olson \& Backus 1985). For typical values of $K_{x y}=10^{2} \mathrm{~m}^{2} \mathrm{~s}^{-1}$, this indicates that convergence zones of size $10 \mathrm{~km}$ and greater will be significant.

Olson \& Backus (1985) showed that this effect could cause significant observed concentration of fish at the edge of Gulf Stream rings. Franks (1992) examined several models of swimming behaviour and their potential to create patchiness at different scales. Chen (1992) suggested that convergence in frontal regions of Great South Channel might explain the

\footnotetext{
${ }^{2}$ The layer thickness $h$ is limited by the total depth $H$ : $\mathrm{h}=\min (25 \mathrm{~m}, H)$

${ }^{3}$ Note that the case of net vertical migration to the surface layer, e.g. of animals exiting diapause, would be accounted for as a net source and would contribute to $R$
}

dense aggregations of Calanus observed there. Below we will confirm this and demonstrate the importance of this effect in other areas of the Gulf as well.

These 2 limiting cases bracket the extremes of our uncertainty about the behaviour. Most commonly, Calanus in the Gulf is thought to inhabit the surface layer. However, there is little data for the earlier stages, which are harder to quantify, and in the process of emergence from diapause the population might well occupy a significant portion of the water column. Additionally, Durbin et al. (1995) found deep diel migration in the 1988 SCOPEX study, but essentially none in the following year, and suggested that the diel migration was likely to be in response to the variable presence of predators. Thus it seems that both of our extremes of behaviour have a place in hypothesis testing.

The 2 flow fields are displayed in Figs. $2 \& 3$. The full vertical average is very similar to its Eulerian version displayed in Lynch et al. (1997). The surface layer incorporates an additional Ekman flux and is generally faster. The divergence is significant in several places, especially in the tidally rectified areas north of Great South Channel and Georges Bank.

We solve these transport equations using a Galerkin method on the mesh depicted in Fig. 4, which coincides approximately with the coverage of the MARMAP data.

\section{Population dynamics}

The terms $R_{l}$ (no. $\mathrm{m}^{-3} \mathrm{~d}^{-1}$ ) represent the local rate of change in concentration due to population dynamics: reproduction, development and mortality. These vital rates are dependent upon local environmental conditions (e.g. temperature, food and predators).

\section{Stages}

A stage-based approach is used. The natural staging involves 13 morphologically distinct stages: egg, 6 naupliar stages, and 6 copepodite stages, the last being the adult copepod (Marshall \& Orr 1955). We have expanded these basic stages to 16 , to account for different environmental influences and behaviour. One of the extra stages accounts for diapausing copepodites. This allows differential mortality and development during diapause, as well as differential depth preference which is critical to the physical coupling. Three adult states account for sexual development following $\mathrm{C} 5$. Knowing that males have a higher mortality in the field, new adults are divided 

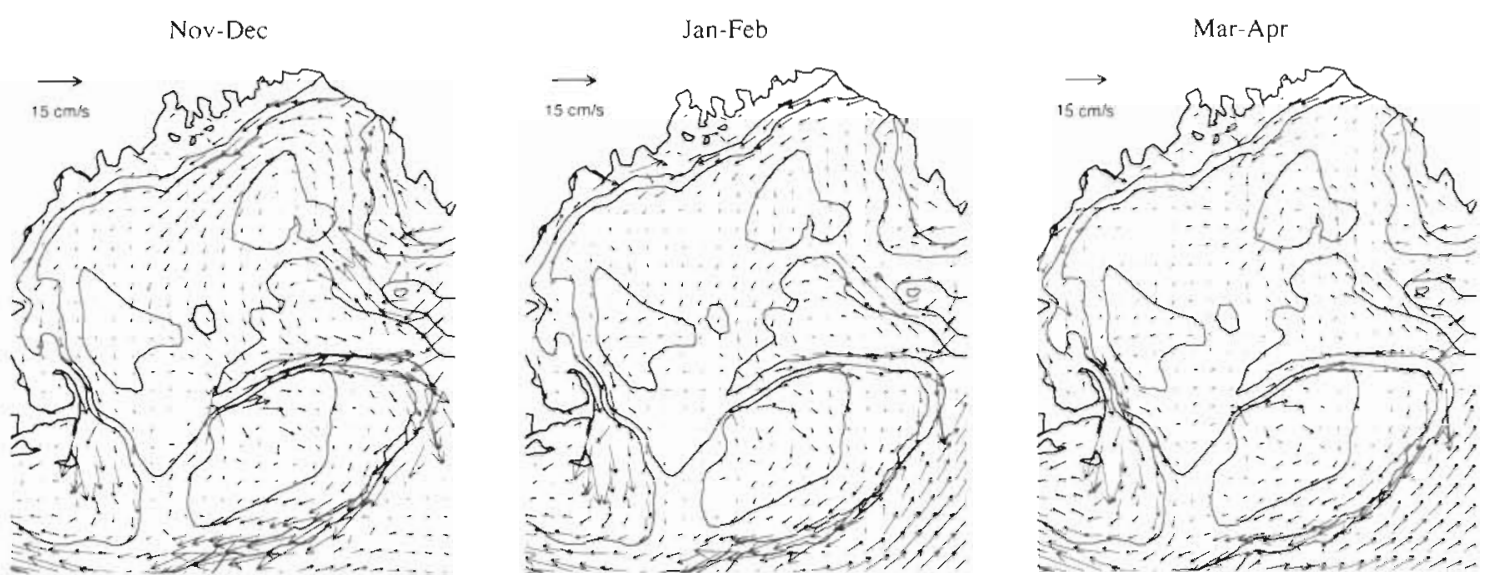

Fig. 2. Vertically averaged Lagrangian velocity for the bimonthly seasons indicated

evenly into males and females as they molt from C5. To account for the time lag between molting to adulthood and the completion of the final stages of oogenesis, we distinguish between prereproductive (or immature) females and those which are able to reproduce. Female fertilization is ignored as a nonlimiting phenomenon. ${ }^{4}$

${ }^{4}$ Fertilization is thought to occur once for life, at the transition from $\mathrm{C} 5$ when male abundance is assumed
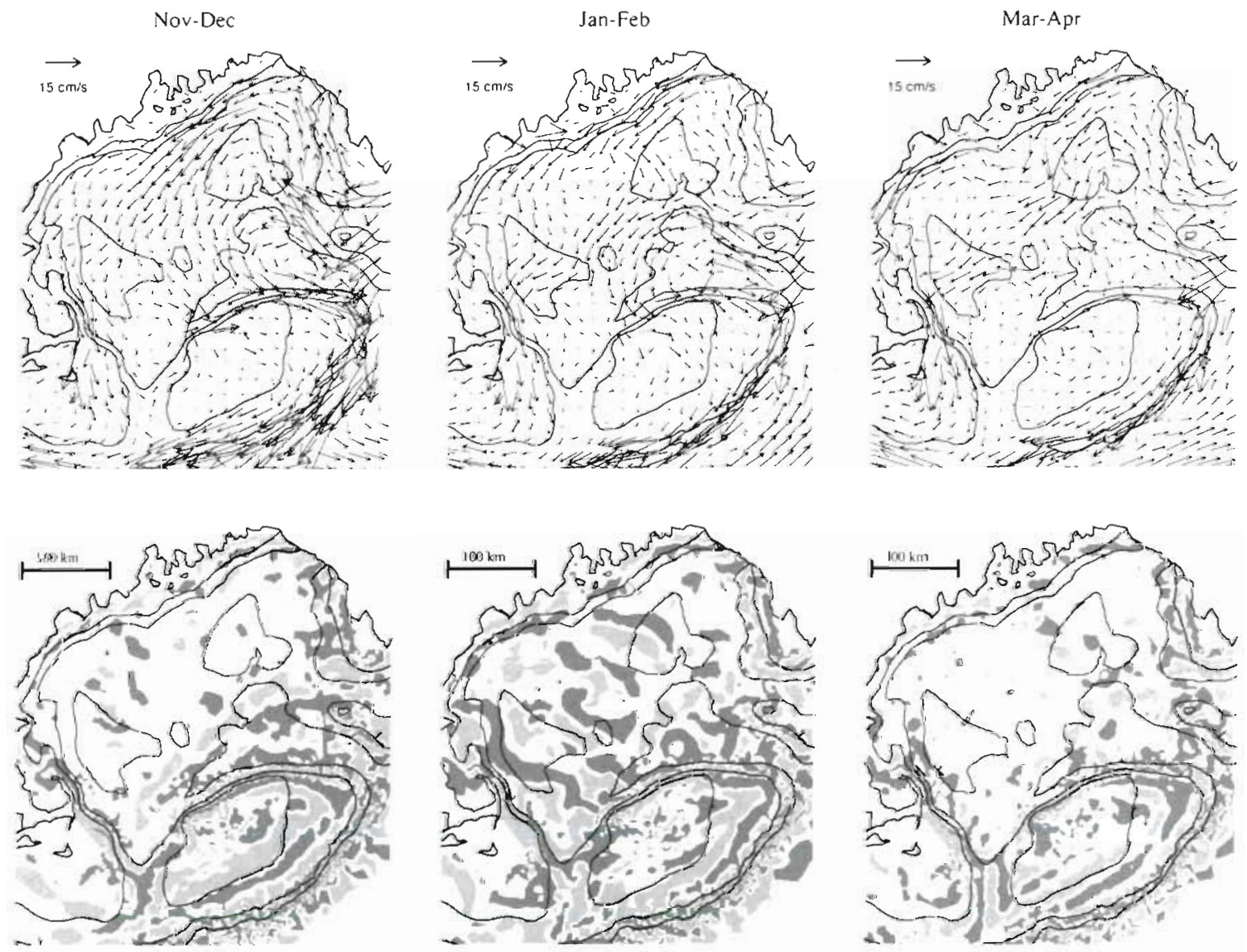

Fig. 3. Average surface layer (top $25 \mathrm{~m}$ ) Lagrangian residual velocity and divergence. Dark grey indicates zones of convergence where surface organisms are concentrated at instantaneous rates $>0.02 \mathrm{~d}^{-1}$; light grey indicates divergence where surface-layer dilution occurs at rates $<0.02 \mathrm{~d}^{-1}$ 
Fig. 4. Finite element mesh ('MARMAP1') used in this study. The boundaries approximate those of the MARMAP sampling. The basic discretization is identical to the ' $\mathrm{G} 2 \mathrm{~S}$ ' mesh used in previous studies (Lynch et al. 1996), with refinement

Mathematically, we have a conveyor belt among successive stages:

$$
R_{i}=\frac{C_{i-1}}{D_{i-1}}-\frac{C_{i}}{D_{i}}-\mu_{2} C_{i}
$$

where $D_{i}$ is the stage duration and $\mu_{i}$ is the mortality rate for stage i. Appropriate adjustments at the end points and adult branch points are implied. Stages with duration exceeding $1 \mathrm{~d}$ (at $5^{\circ} \mathrm{C}$ ) are subdivided to control developmental diffusion which is inherent in the Eulerian approach. (Fig. 5 demonstrates that this is successful.)

\section{Development}

Average developent times $D_{i}$ are sensitive to both temperature and food availability. Generally, increasing temperature $T$ decreases the stage durations, $D_{l}$. These are traditionally related through Belehradek equations of the form:

$$
D_{1}(T)=a_{i}(T-\beta)^{\alpha}
$$

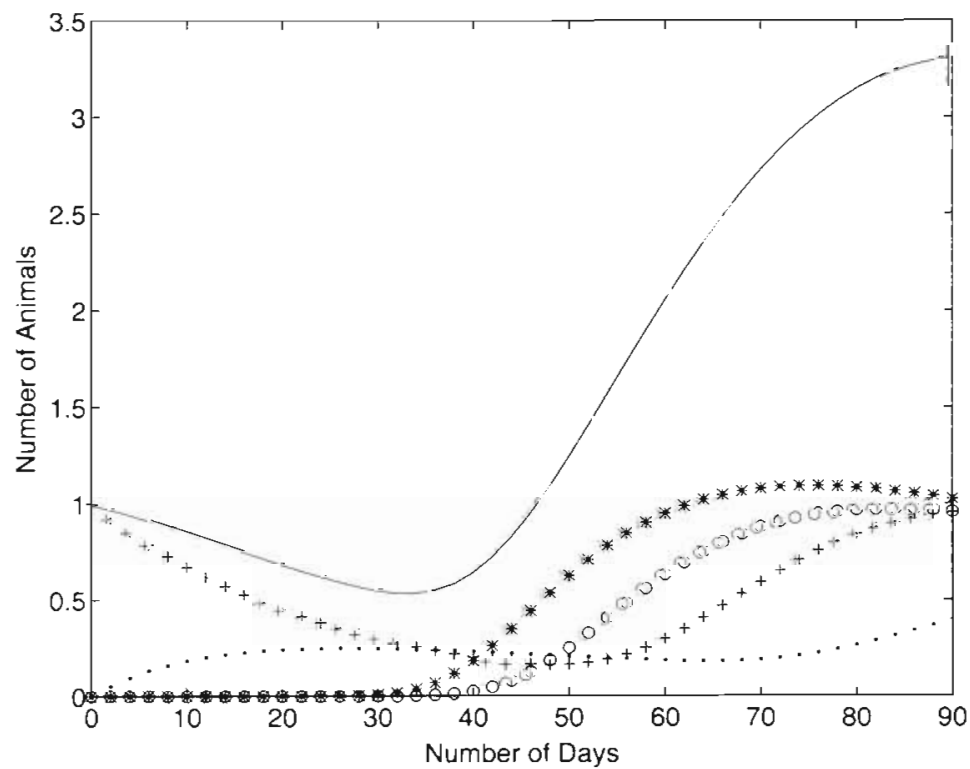

Fig. 5. Population dynamics for the base model at a fixed temperature of $5^{\circ} \mathrm{C}$ and with no gains or losses from physical transport. The generation $1\left(G_{1}\right)$ animals are sterile. The initial population is a unit cohort of diapausing animals. The diapausing animals molt to adult at an instantaneous rate of $0.03 \mathrm{~d}^{-1}$. Plotted are the time-histories of $\mathrm{C} 3(*), \mathrm{C} 4(0)$, C5 $(+)$ and adult $(\cdot)$, and the total $(-)$ of these 
Table 1 Vital rates for Calanus finmarchicus (days) at 5 and $10^{\circ} \mathrm{C}$. Development times are given by the Belehradek form $D(T)=a(T-\beta)^{\alpha}$ with $\alpha=-2.05$ and $\beta=-9.11^{\circ} \mathrm{C}$

\begin{tabular}{|c|c|c|c|c|c|}
\hline & Belehradek $a$ & $D\left(5^{\circ} \mathrm{C}\right)$ & $D\left(10^{\circ} \mathrm{C}\right)$ & Satiation ( $\mu \mathrm{g} \mathrm{C}{ }^{-1}$ ) & Mortality $\left(\% \mathrm{~d}^{-1}\right)$ \\
\hline Eggs & 595 & 2.62 & 1.41 & - & 20 \\
\hline N1 & 387 & 1.70 & 0.91 & - & 15 \\
\hline N2 & 582 & 2.56 & 1.38 & - & 15 \\
\hline N3 & 1387 & 6.10 & 3.28 & 100 & 15 \\
\hline N4 & 759 & 3.34 & 1.79 & 100 & 15 \\
\hline N5 & 716 & 3.15 & 1.69 & 100 & 15 \\
\hline N6 & 841 & 3.70 & 1.99 & 100 & 15 \\
\hline $\mathrm{C} 1$ & 966 & 4.25 & 2.28 & 150 & 5 \\
\hline $\mathrm{C} 2$ & 1137 & 5.00 & 2.69 & 150 & 5 \\
\hline C3 & 1428 & 6.28 & 3.37 & 150 & 5 \\
\hline $\mathrm{C} 4$ & 2166 & 9.53 & 5.12 & 150 & 5 \\
\hline C5 & 4083 & 17.97 & 9.65 & 150 & 5 \\
\hline Males & - & - & - & - & 10 \\
\hline Immature females & 1757 & 7.73 & 4.15 & 150 & 2 \\
\hline Mature females & - & - & - & - & 2 \\
\hline Interclutch interval & 218 & 0.96 & 0.52 & 150 & - \\
\hline Diapause & - & - & - & - & 1 \\
\hline
\end{tabular}

where $\beta$ and $\alpha$ are constants and $a_{i}$ is a stage varying parameter. Parameters used in this model for egg through $\mathrm{C} 5$ are based on a recent rearing experiment by R. Campbell (pers. comm.) and appear in Table 1. The estimate for immature females is based on Plourde \& Runge (1993). Stage durations of males and mature females are treated as infinite

Food effects are less precisely known. The stage duration equation above holds for maximal development rate assuming non-limiting food concentrations $\left(\geq 400 \mu \mathrm{g} \mathrm{C} \mathrm{l}^{-1}\right)$. We assume that eggs, N1 and N2 do not feed (Marshall \& Orr 1955, Carlotti \& Radach 1996). For the other stages, we expect that stage durations will increase as food concentrations are reduced. Campbell (pers. comm.) indicates an increase by almost a factor of 1.5 at food levels of $50 \mu \mathrm{g} \mathrm{C} \mathrm{l}^{-1}$ and a factor of 2 at food levels of $25 \mu \mathrm{g} \mathrm{C} \mathrm{I}^{-1}$. Durbin et al. (1995) observed stage durations of $24.8 \mathrm{~d}$ for $\mathrm{C} 4 \mathrm{~s}$ at $11^{\circ} \mathrm{C}$ in the field, under food-limited conditions.

Completion of the final stages of oogenesis is highly dependent upon external food supply (Plourde \& Runge 1993, Hirche 1996a, Niehoff \& Hirche 1996, Runge \& Plourde 1996). Thus the stage duration of the immature female is lengthened as food abundance is reduced. The literature suggests that development in the field can be delayed by as much as 1 mo (Hirche 1996a) when food is scarce. This could have a significant effect on the first generation as it would delay its initiation and displace it 'downstream' in the advective system.

As a point of departure, food effects on development are modeled by decreasing development rate $(1 / D(T))$ linearly toward zero when food is below a satiation value. [Equivalently, development time varies inversely
Table 2. Other model parameters

$\begin{array}{lc}\text { Clutch size } & 50 \\ \text { Male fraction at molt } & 0.5 \\ \text { Male mortality multiplier } & 5 \\ \text { Carbon/chlorophyll ratio } & 100\end{array}$

with food availability, with the Belehradek function Eq. (10) representing the lower limit.] The baseline parameters used are summarized in Tables $1 \& 2$.

\section{Egg production}

Spawning is an intermittent process. A mature female releases a clutch of eggs over a short period of time (minutes) with longer time intervals (of the order of $1 \mathrm{~d}$ ) between clutches (Hirche 1996a). Generally the interclutch interval $d$ is considered to be sensitive to variations in the environment, while by comparison the clutch size is relatively insensitive. Averaging over many individuals, we model this as a continuous process with constant clutch size of 50 eggs per female:

$$
R_{e}=\frac{50 C_{F}}{d}-\frac{C_{e}}{D_{e}}-\mu_{e} C_{e}
$$

The subscripts e and $F$ refer to egg and female. Both laboratory and field experiments have found temperature and egg production to be positively correlated (Hirche 1990, Plourde \& Runge 1993, Runge \& Plourde 1996, Hirche \& Kwasniewski 1997, Hirche et al. 1997). Miller et al. (1998) fit the Hirche et al. data for clutch interval variations with temperature using the 
Belehradek function:

$$
d=218 \cdot(T+9.11)^{-2.05}
$$

and we use this relation in Table 1.

The above relation holds for superabundant food levels (>400 $\mathrm{\mu g} \mathrm{C}^{-1}$ in Hirche 1990). As food concentration is reduced, egg production decreases with a few days' time lag before the effect is seen (Hirche 1990, Runge \& Plourde 1996). In laboratory experi-

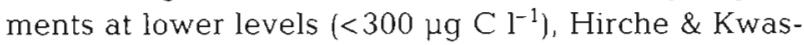
niewski (1997) observed both a tendency for increased interclutch interval and decreased clutch size. Plourde \& Runge (1993) also saw pronounced reduction in egg production in the field for ambient levels $<1.25 \mu \mathrm{g} \mathrm{chl}$ $\mathrm{I}^{-1}$. We approximate this effect in the same way as development rate: decreasing the egg production rate linearly to zero when food is below a satiation value $\left(150 \mu \mathrm{g} \mathrm{C}^{-1}\right.$ ). Like the food effect on female development, this is a critical parameterization relative to the initiation of generation 1 .

\section{Mortality}

Stage-dependent mortality is represented. Generally, it is assumed highest for earlier life-stages (Aksnes \& Blindheim 1996). Male mortality is assumed higher than female mortality (a factor of 5 herein), reflecting observations of relative abundance in the field.

Predation is likely to be the dominant source of mortality (Davis 1984a, c, Madin et al. 1996, Sullivan \& Meise 1996) at least over Georges Bank. It is not easily quantified. Predation risk from visual predators would decrease with depth (Aksnes \& Blindheim 1996), and diel migration may be triggered by the presence of predators (Durbin et al. 1995). At this time, the details of predator abundance and distribution, and the behavioural response to same, must await a fuller understanding.

Temperature and food effects on mortality are not represented directly. Hirche (1987) found that Calanus has a high tolerance to temperature variation. One direct effect of food limitation would be to increase the susceptibility to predation (Kleppel et al. 1996), but we have insufficient empirical support. The effects of temperature and food on stage duration, and therefore on exposure to early stage predation, are captured as indirect effects. Another direct effect would be that of female diet on viability of eggs and early nauplii (Laabir et al. 1995, Uye 1996). This is not represented; instead it is bundled into the limitation on egg production, avoiding the production of eggs which are not viable through stage $\mathrm{N} 2$.

We have adopted baseline mortality estimates in Tables $1 \& 2$ as lower limits. Additional detail must be inferred at present.

\section{Base model}

A 'best case scenario' will be assumed: food satiation and baseline mortality, with temperature effects activated. There is good support for these necessary model elements; in effect they become the 'passive tracer' equivalent for the reproducing system. Properly initialized, the base model will systematically overestimate abundance (low mortality), reproduce too early (no food limitation), and continue reproducing too long (infinite female reproductive life).

Fig. 5 shows the base case population dynamics in the absence of physical transport. Against this baseline, the impacts of food limitation and more detailed mortality can be introduced as needed. The impact of food-limited development time and interclutch interval will be approximated as described above, using bimonthly chlorophyll a data (O'Reilly \& Zetlin 1997, see below). Narrowing the gap between base model results and observations should permit inference about these effects.

\section{Coupled model summary}

Summarizing the main features of the coupled model:

- a detailed circulation model describes the climatology in 2 mo means;

- assumptions about vertical swimming behaviour lead to two 2-D limits which bracket the possibilities: surface-only and depth-averaged transport;

- a 16-stage population dynamics model focuses on the initiation of the growing season through the first generation;

- the base model is idealistic, with low mortality and abundant food.

\section{OBSERVATIONS}

Meise \& O'Reilly (1996) analyzed 10 yr mean abundance of Calanus from the MARMAP program (1977-1987). The data include stages C3 through adult (females + males) combined in 6 bimonthly snapshots, and distributed across 97 spatial tiles covering the Gulf of Maine and Georges Bank. Sampling depth was limited to the upper $200 \mathrm{~m}$. These data were interpolated onto the finite element mesh (Fig. 4) using objective analysis. Additional snapshots were prepared in the same way to provide resolution at monthly intervals (Meise pers. comm.). The resulting sequence from December 1 to April 1 appears in Fig. 6. The fall data are dominated by C5s, with some $\mathrm{C} 4$ and adults, occupying the central 

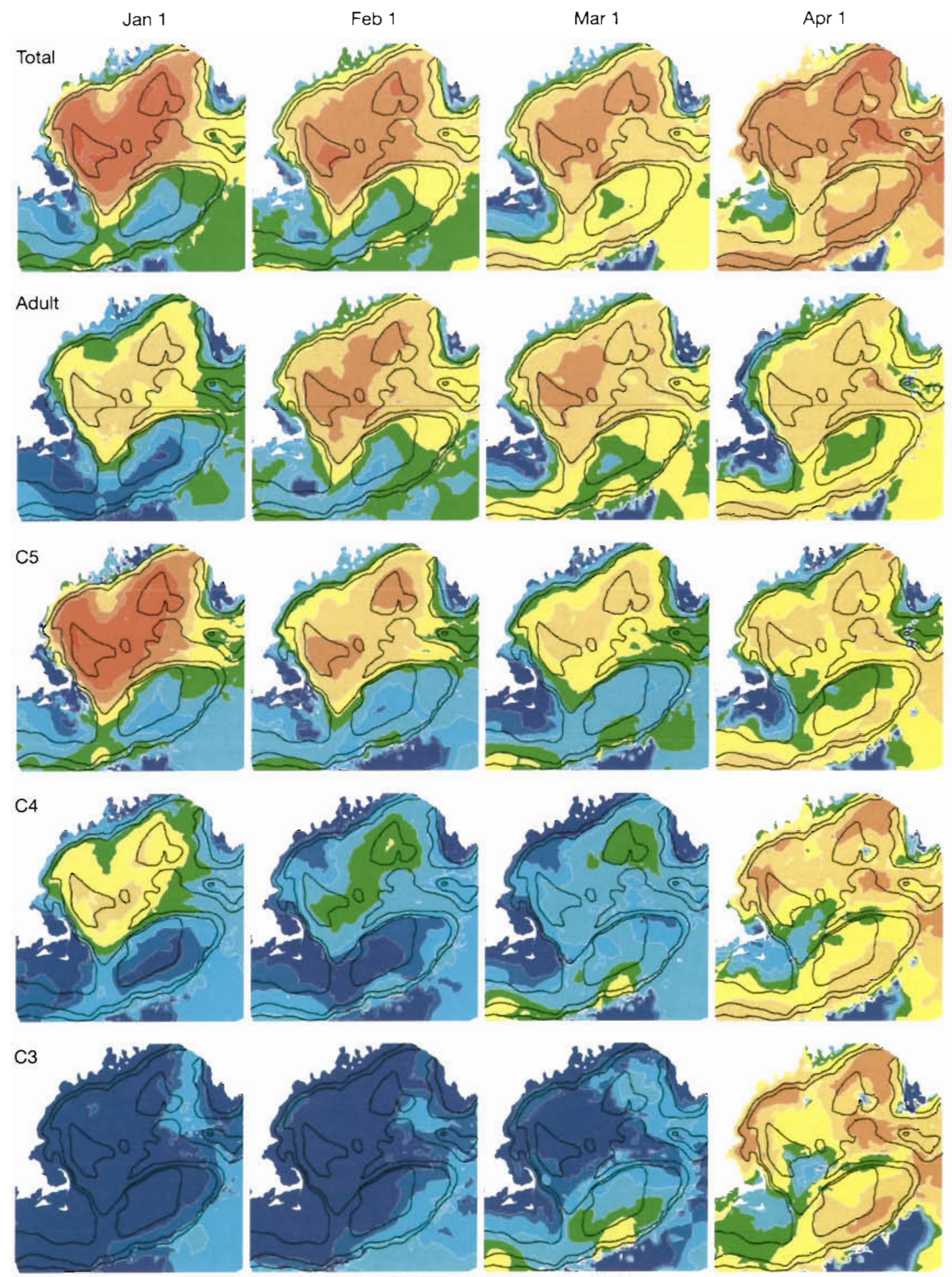

$\begin{array}{llllllllllll}0.0 & 0.5 & 1.0 & 1.5 & 2.0 & 2.5 & 3.0 & 3.5 & 4.0 & 4.5 & 5.0\end{array}$

Fig. 6. Decadally averaged bimonthly Calanus abundances $\left(A=\right.$ no. $\mathrm{m}^{-2}$ in the upper $\left.200 \mathrm{~m}\right)$ centered in time at the dates indicated. These were objectively interpolated from Meise \& $O^{\prime}$ Reilly (1996). Units are $\log _{10}(A+1)$

Gulf and decaying at about $1 \% \mathrm{~d}^{-1}$, consistent with a diapausing population. There are well-defined population centers over Jordan and Wilkinson Basins.
During December and January the adults increase while copepodites decrease, indicative of activation of the resting stock. Through March 1 there is a general 


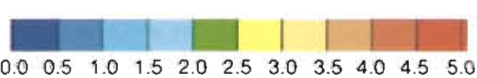

Fig. 7. Decadally averaged bimonthly chlorophyll concentration, centered in time at the dates indicated. These were objectively interpolated from O'Reilly \& Zetlin (1997). Units are $\mu \mathrm{g}$ chl $a 1^{-1}$, averaged over the upper $75 \mathrm{~m}$
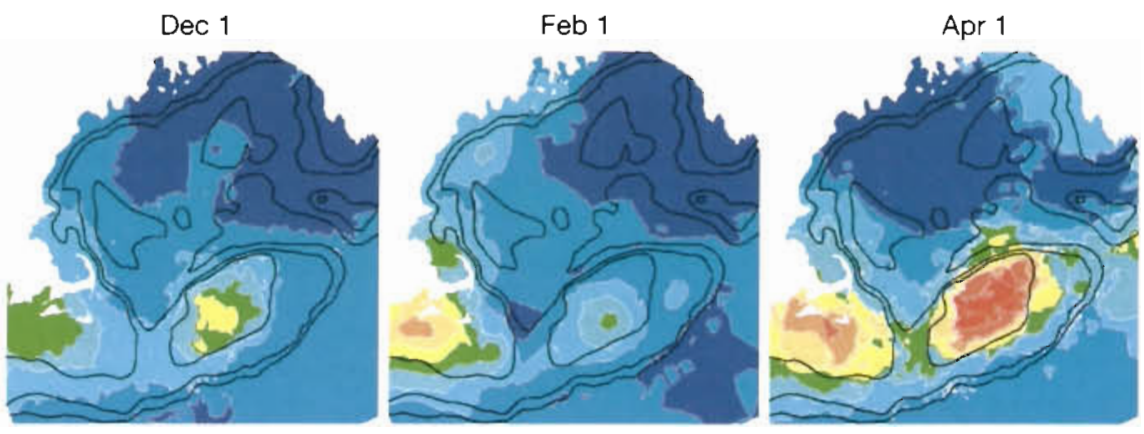

decay in abundance. New copepodites $\mathrm{C} 3$ and above emerge during March. By April 1 the first generation is well established in stages $\mathrm{C} 3$ through $\mathrm{C} 5$, but has not as yet reached adulthood.

Based on these observations, we initiate our simulations on January 1 . This puts us at the start of the growing season. The data provide initial conditions for $\mathrm{C} 3$, $\mathrm{C} 4, \mathrm{C} 5$, and adults. The unobserved smaller stages are set to zero. This assumption would be inappropriate later in the year and would confound any interpretation. The data also support activation of the diapausing copepodites on a 1 to 2 mo timescale.

O'Reilly \& Zetlin (1997) provide a similar decadal average of chlorophyll abundance in the upper $75 \mathrm{~m}$. These data have been processed in the same way and appear in Fig. 7. Peak abundance occurs in March-April, well after the initiation of the Calanus cycle apparent in the data. Clearly the emergence of generation $1 \mathrm{C} 3$ and older by March would indicate that spawning and development of eggs and nauplii is occurring in the early stages of the phytoplankton bloom.

Assuming a carbon/chlorophyll ratio of the order of 100 , and the parameters in Table 1, food abundance appears to limit female maturation, egg production, and development over much of the region. The exceptions are the central shoal area of Georges Bank, and certain coastal areas.

\section{RESULTS}

We made several simulations with the goal of building inference about the dynamics contributing to observed MARMAP distrubutions. Generally, all simulations are started on January 1 and run for 60 to $90 \mathrm{~d}$, with the physical fields interpolated linearly within the climatology.

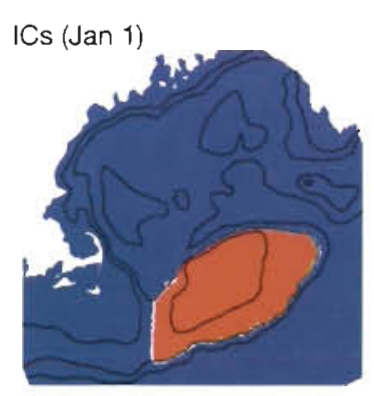

\section{Passive tracer simulations}

Here we use a single passive stage, representing a total population during this period with no mortality, to answer several baseline questions. 'Passive' in this context indicates a conservative tracer; when confined in the surface layer, active depth regulation is implied.

How retentive is Georges Bank? Fig. 8 shows the results of a passive tracer initially occupying Georges Bank ( $C=1$ within the $100 \mathrm{~m}$ isobath) but absent from the rest of the system. The washout effect of the circulation is clearly shown, advecting the initial Bank pop-

$\begin{array}{lllllllllllll}0.0 & 0.1 & 0.2 & 0.3 & 0.4 & 0.5 & 0.6 & 0.7 & 0.8 & 0.9 & 1.0\end{array}$

Fig. 8. Georges Bank retention simulation; passive tracer. Initial conditions were concentration $\left(C=\right.$ no. $\left.\mathrm{m}^{-3}\right)$ of unity on the Bank (defined by the $100 \mathrm{~m}$ isobath and the $69^{\circ} \mathrm{W}$ meridian) and zero off-Bank. Results are shown in units of no. $\mathrm{m}^{-3}$ at $30 \mathrm{~d}$ intervals
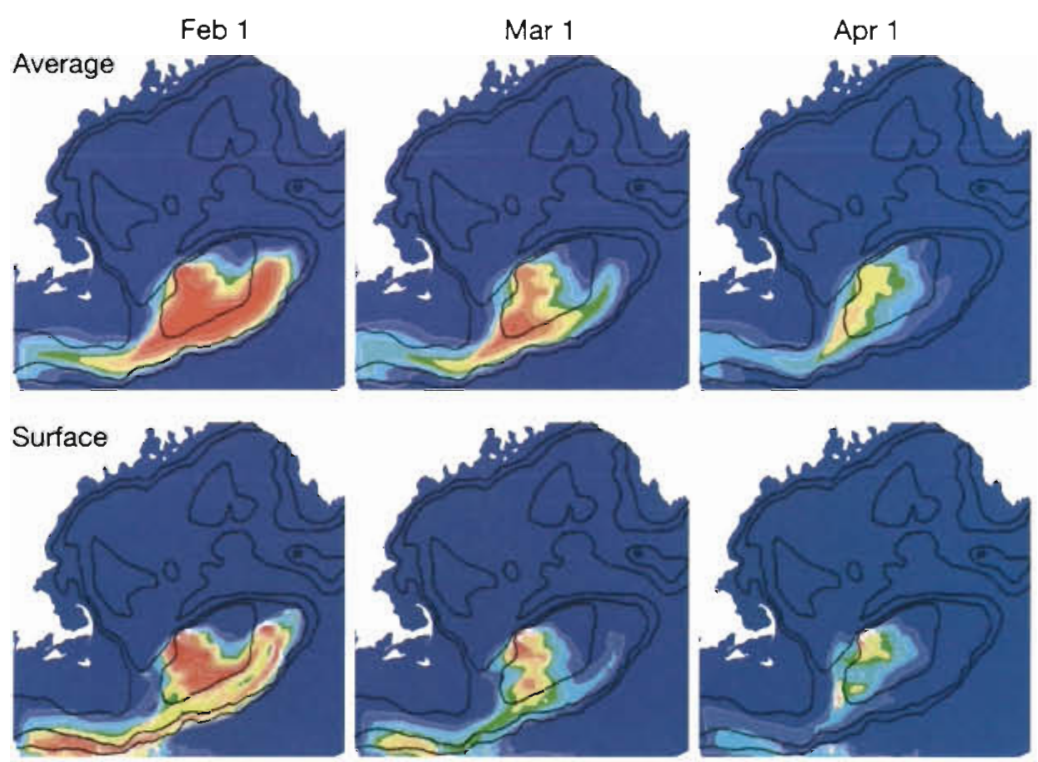

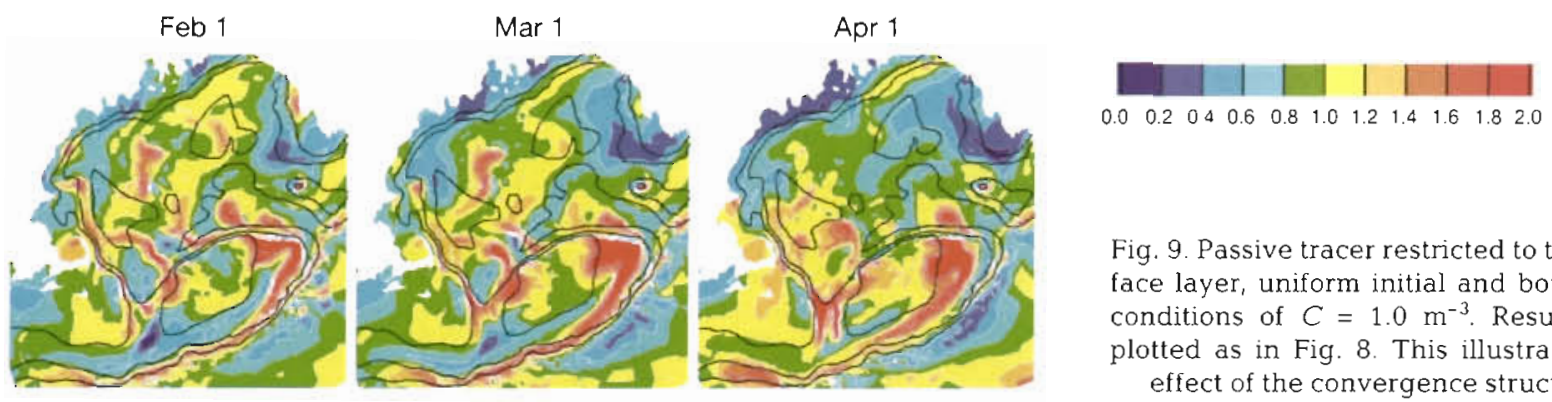

Fig. 9. Passive tracer restricted to the surface layer, uniform initial and boundary conditions of $C=1.0 \mathrm{~m}^{-3}$. Results are plotted as in Fig. 8. This illustrates the effect of the convergence structure

ulation to the southwest and restocking the Bank from the Gulf. The surface layer washout is particularly pronounced. These simulations illustrate constraints on local production which would have to be met for an in situ population to be self-sustaining. They also illustrate the potential for continuous resupply from offbank sources, in agreement with Davis (1984b).

What patterns are created by the surface layer convergence? Fig. 9 shows the result of a passive tracer simulation in the surface layer with uniform initial and boundary conditions $C=1$ throughout the system. With the tracer confined to the upper $25 \mathrm{~m}$, fluid convergence has a concentrating effect. The $30 \mathrm{~d}$ results indicate important hot spots over Northeast Peak and Northwest Georges Bank, and 'lanes' connecting to these from the Gulf. Additional narrow lanes occur along the Northern and Southern Flanks, as well as along the western shoal of Great South Channel. These lanes can be seen in previous studies of Lagrangian particle trajectories (e.g. Hannah et al. 1998, Miller et al. 1998) wherein they at- tract near-surface particles. The hot spots themselves are less obvious in trajectory studies but have obvious ecological importance. In particular, the hot spot over Northeast Peak covers the primary spawning ground for Georges Bank cod in March. The lane in Great South Channel is in the vicinity of right whale aggregation later in the year. All of these features occur at the expense of adjacent cold spots.

The $60 \mathrm{~d}$ result shows the aging and surface transport of the $30 \mathrm{~d}$ pattern.

How do the deep basins affect the Bank? Jordan and Wilkinson Basins are clearly population centers for resting stock in late fall; Georges Basin may also be a center. ${ }^{5}$ Figs. $10 \& 11$ show the fate of passive tracers released as Gaussian bumps over these 3 deep basins. Generally, all 3 basins contribute populations to the Bank. The vertically averaged flow provides slower

${ }^{5}$ The maximum sampling depth is $200 \mathrm{~m}_{\text {; }}$ Georges Basin reaches $370 \mathrm{~m}$
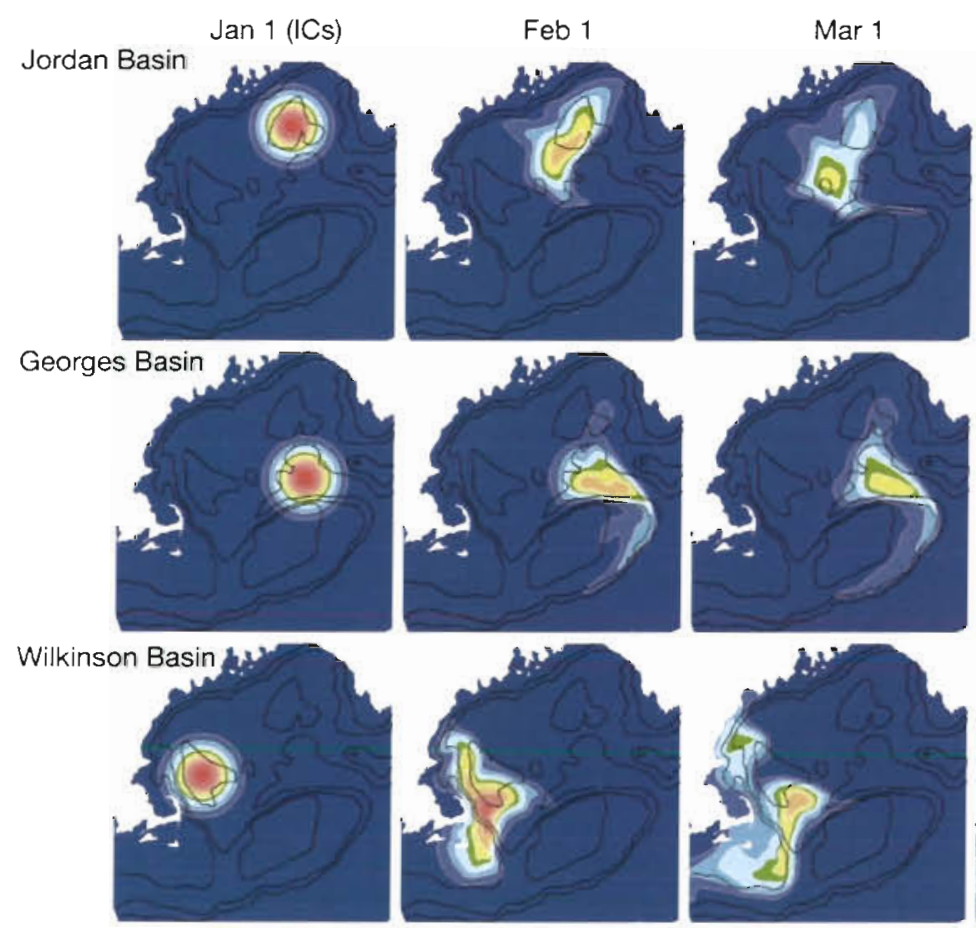

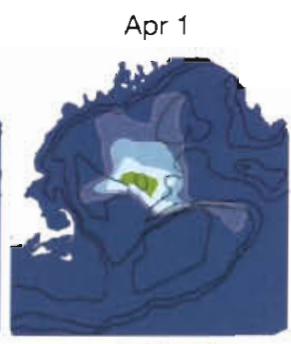

\begin{tabular}{lllll|lll|l|l|l|l}
\hline & & $\mid$ & $\mid$ & $\mid$ & $\mid$ & $\mid$ & $\mid$ & $\mid$ & $\mid$ \\
0.0 & 0 & 0.2 & 0.3 & 0.4 & 0.5 & 0.6 & 0.7 & 0.8 & 0.9 & 1.0
\end{tabular}
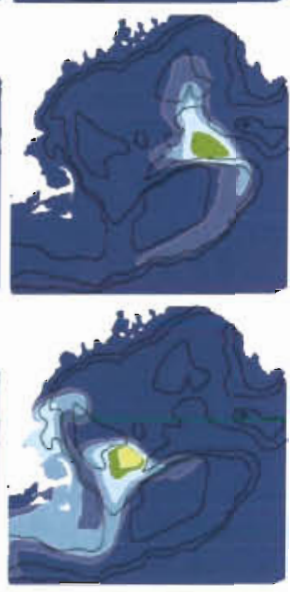

Fig. 10. Basin source simulations; passive tracer in the vertically averaged flow. Initial conditions are Gaussian distributed concentration $\left(C=\right.$ no. $\left.\mathrm{m}^{-3}\right)$ fields centered over the 3 deep basins. Results are plotted as in Fig. 8 
Fig. 11. Basin source simulations; passive tracer in the surface flow. Initial conditions are Gaussian distributed concentration $(C=$ no. $\mathrm{m}^{-3}$ ) fields centered over the 3 deep basins. Results are plotted as in Fig. 8

$\begin{array}{llllllllllll}0.0 & 0.1 & 0.2 & 0.3 & 0.4 & 0.5 & 0.6 & 0.7 & 0.8 & 0.9 & 1.0\end{array}$
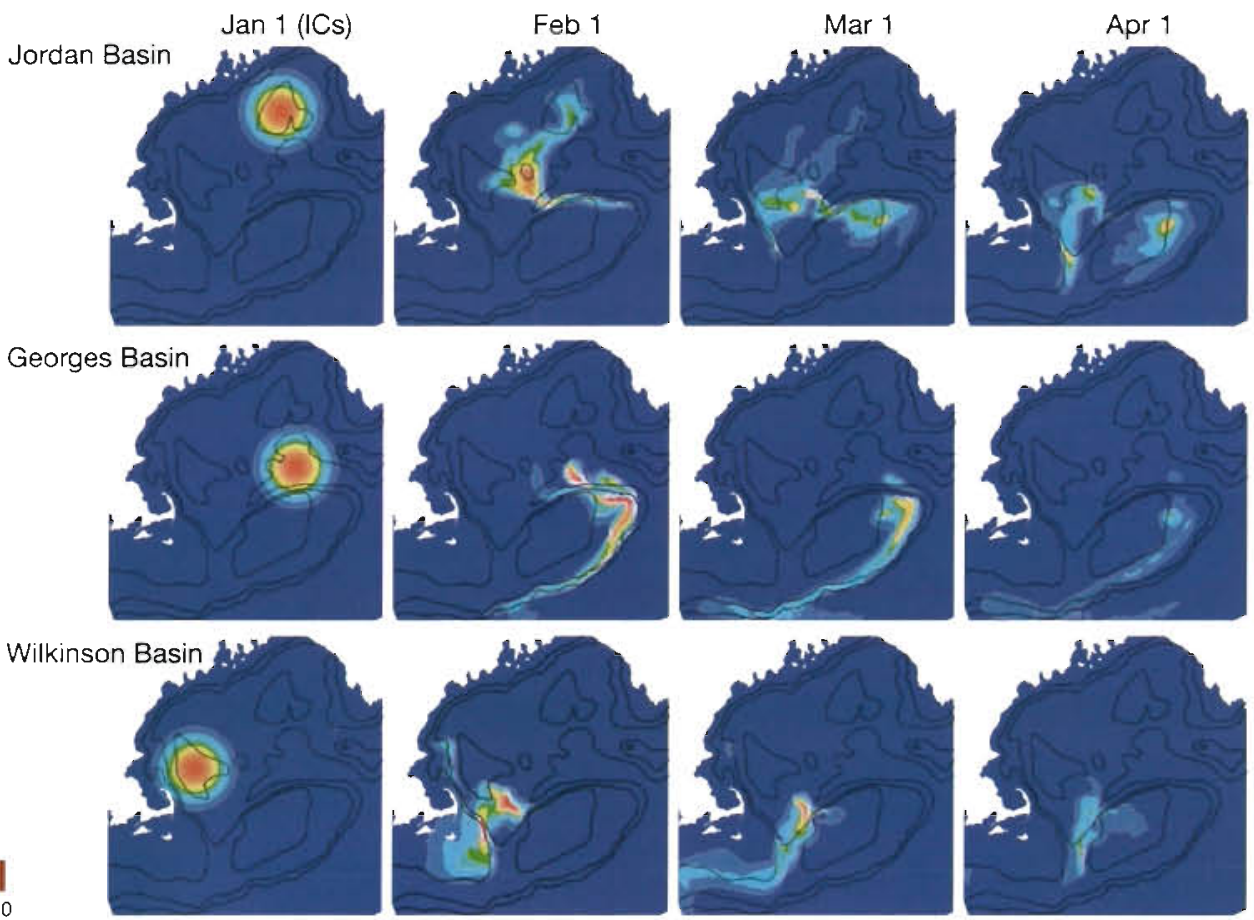

and smoother distributions, being steered by the deep topography in the Gulf and tending to go around the Bank rather than over it. The surface layer is faster and crosses topography more freely; it also shows the concentrating effect of the convergence structure.

From Jordan Basin, the average flow is first to the southwest, with the center of the plume situated after $60 \mathrm{~d}$ over the sill between Georges and Wilkinson Basins. The leading edge of the plume branches southeast toward the Northern Flank of Georges Bank. At $90 \mathrm{~d}$ it is still centered in the Gulf of Maine. The surface flow is faster, with the $30 \mathrm{~d}$ result resembling the $60 \mathrm{~d}$ vertically averaged result. At $60 \mathrm{~d}$ the surface plume has bifurcated with downstream branches over Wilkinson Basin and Georges Bank, the latter spilling over the Northern Flank and populating the Northeast Peak and central shoal area. At $90 \mathrm{~d}$ the surface plume is bimodal. One mode is spreading over the Northeast Peak and Southern Flank of the bank; the other is in the southern Wilkinson Basin, with leakage through Great South Channel.

From Georges Basin the average flow is toward and then around Georges Bank. At 60 d the center of mass is still over the basin, and that pattern is retained through Day 90. The surface flow at $30 \mathrm{~d}$ is further downstream, and concentrated on the Northeast Peak. of the Bank. Later at $60 \mathrm{~d}$ the surface plume is elongated over the Southern Flank; but the concentration on the Northeast Peak remains, shifted south by the advection. At $90 \mathrm{~d}$ the surface plume is washing out of the system along the Southern Flank.
From Wilkinson Basin the average flow retains the population center in the Basin, shifted slightly to the southeast. The basin is lossy, with a well-defined exit path southward through Great South Channel. As in the other basins, the surface layer pattern at $30 \mathrm{~d}$ resembles the average pattern at $60 \mathrm{~d}$, but the convergence zones have concentrated the retained population and also narrowed the exit lane along the western side of Great South Channel. At $60 \mathrm{~d}$ the retained population has moved onto the western end of Georges Bank with significant presence in the recirculation zone between the 100 and $60 \mathrm{~m}$ isobaths. The $90 \mathrm{~d}$ result shows advection of this cohort around the central cap of the Bank.

These results confirm the ability of the deep basins to deliver populations to Georges Bank during the initiation of the growing season, in agreement with Davis (1987). The behavioural limits - average versus surface layer-influence the results a great deal. The surface transport is significantly faster (roughly a factor of 2) and more directly connected to the bank. The deeper circulation is more retentive at the points of origin.

What are the influences of inflow from unmodeled upstream sources? Simulations will be initialized with MARMAP data; implied is the dependence of subsequent distributions on initial conditions. However there are 3 points of entry: the Scotian Shelf, the Bay of Fundy, and the slope water. We have no simple way to specify the population structure entering at these points, since (1) the first generation will not be visible until it has matured to stage C3, and (2) data at the inflow boundaries are already extrapolated from the 
MARMAP sampling. What is the impact of ignoring inputs on these boundaries?

Fig. 12 depicts a 90 d passive run initiated with $C=0$ everywhere but with $C=1$ maintained on inflow boundaries. Clearly the influence of all 3 'sources' can be seen. In the surface layer we see the Maine Coastal Current entering from the Bay of Fundy and meandering offshore south of Penobscot Bay. The Scotian Shelf inflow invades Browns Bank and eastern Georges Basin, with a branch crossing to Georges Bank. On the bank there is a convergence on the Northeast Peak, as well as an exit lane along the Southern Flank between the 100 and $200 \mathrm{~m}$ isobaths. Finally, the offshore eastward-flowing currents are entering the model but remain uninvolved with the Bank and the basins. The deeper, average circulation is a muted version, with similar patterns but less penetration on this time scale.

For our purposes, 2 of the influences
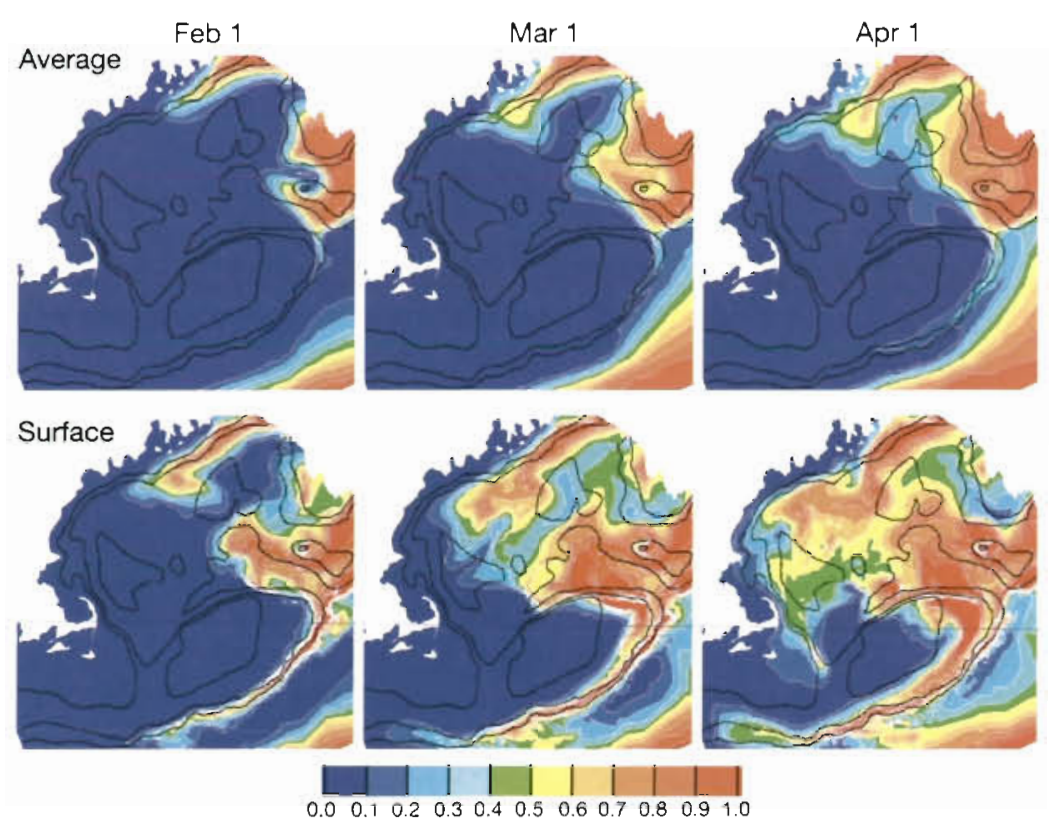

Fig. 12. Continuous injection of $C=1.0 \mathrm{~m}^{-3}$ along the inflow boundaries; passive tracer. (Initial conditions were an empty domain,) Results are plotted as in Fig. 8

(Bay of Fundy and offshore) appear to be relatively benign but the Scotian Shelf is a concern, especially with the surface circulation. We will have to either remain agnostic about model/data comparisons in the regions of its influence, or reach beyond the data to formulate credible boundary conditions. ${ }^{6}$

\section{Transport and fate of the resting stock}

The data indicate that stages C.3 through adult represent solely generation 0 through March 1, with generation 1 entering the data at stage C3 beginning in earnest on April 1. Therefore in this section we model stages $\mathrm{C} 3$ through adult as a nonreproducing population for $60 \mathrm{~d}$, initialized on January 1 with the MARMAP distributions. Boundary inflows will be empty, so the simulation will be strictly the response to initial conditions. The question: is total abundance and distribution during this early period comsistent with the circulation?

The data indicate a decay of total Calanus over the period, approximating $2 \% \mathrm{~d}^{-1}$, consistent with a combination of baseline mortalities from Table 1. Copepodites (the sum of stages C 3 through C5) decay at

\footnotetext{
${ }^{6}$ It is possible that inflow $\mathrm{BCs}$ could be inferred from the interior data. However that would require inverting both the behaviour and the population dynamics to obtain the unobserved early stages. We leave that problem for future investigation
}

approximately $4 \% \mathrm{~d}^{-1}$ over the period, which we interpret as the sum of baseline mortality $\left(1 \% \mathrm{~d}^{-1}\right)$ plus development to adult $\left(3 \% \mathrm{~d}^{-1}\right)$. We use these overall decay rates to constrain the $G_{0}$ copepodite dynamics in this section.

There is a fundamental problem in the MARMAP initialization. The sampling was limited to the upper $200 \mathrm{~m}$, while all 3 deep basins in the Gulf exceed this depth. Therefore we cannot rule out the possibility of additionaI, very deep animals. Since the data already indicate population centers over the basins, these are potentially very important. Sameoto \& Herman (1990) and Herman et al. (1991) found this to be the case in the deep basins on the Scotian Shelf; it is reasonable to anticipate the same in the Gulf of Maine. We imagine, therefore, deep unexplored reservoirs of diapausing copepodites within the $200 \mathrm{~m}$ isobaths.

\section{Total Calanus}

The simplest simulation is revealing. We simulated total Calanus decaying at $2 \% \mathrm{~d}^{-1}$, transported in the vertically averaged flow. Fig. 13 shows the results after 30 and $60 \mathrm{~d}$. The Gulf of Maine populations are transformed in a reasonable manner with general persistence of the initial pattern. The impact of the empty boundary inflows clearly dominates the distribution along the northern Gulf shore, along Nova Scotia, and over Browns Bank. Georges Bank populations are too large on the Northeast Peak. The population in the 


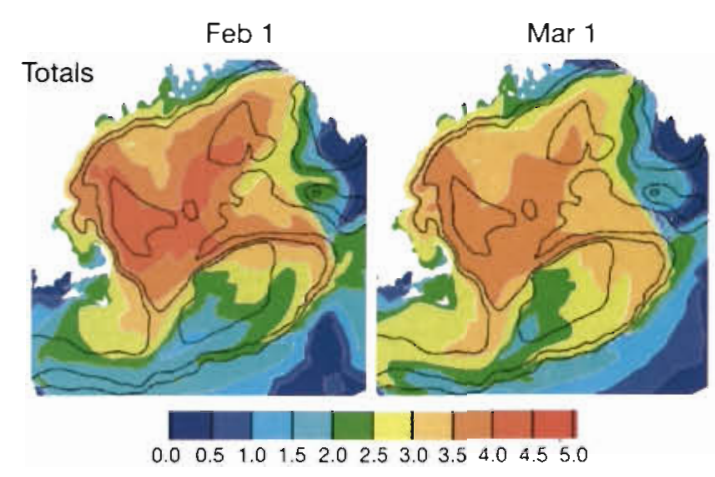

Fig. 13. Transport and decay of total Calanus (C3 to Adult) in the vertically averaged flow. This simulation was initialized from MARMAP data on January 1. Instantaneous mortality was $0.02 \mathrm{~d}^{-1}$. Resulting abundances are shown at $30 \mathrm{~d}$ intervals. To allow for direct comparison, displayed units are identical to the MARMAP data $\left[\log _{10}(A+1)\right.$, where $A=$ no. $\mathrm{m}^{-2}$ in the upper $200 \mathrm{~m}$ ]

exit region including southern Wilkinson Basin, Great South Channel, and Nantucket Shoals is also too large. An additional missing feature is the small local maximum occurring along the Southern Flank. This appears in the data in all stages on March 1 , which we interpret as a $G_{1}$ cohort advecting from either Georges Basin, the Scotian Shelf, or the slope water.

Probably the most important discrepancy occurs over Jordan Basin. The data show strong persistence there; the simulations show washout. The more extreme behavioural assumption-transport in the surface layer, appropriate to the adult portion of this cohort-would only exacerbate the washout effect. Examination of the passive tracer runs reveals that the boundary inflows are unlikely to contribute to the center of Jordan Basin. So we deduce the need for in situ sources to repair this defect. The likely mechanism is activation of unmeasured deep, immobile populations as suggested above.

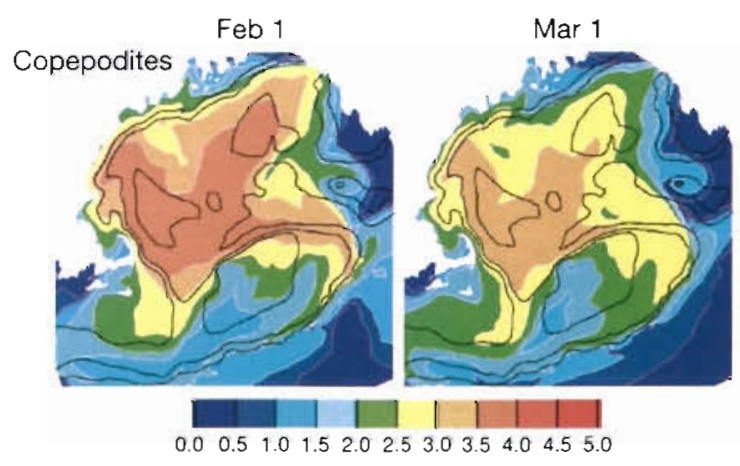

Fig. 14. Transport and decay of copepodites (C3 to C5) in the vertically averaged flow. This simulation was initialized from MARMAP data on January 1 Net instantaneous decay (mortality plus development) was $0.04 \mathrm{~d}^{-1}$ Results are plotted as in Fig. 13

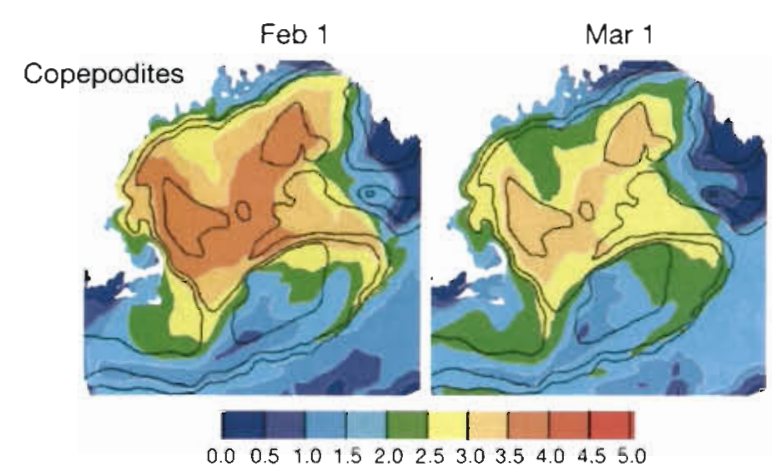

Fig. 15. Total copepodites as in Fig. 14, with deep ( $\geq 200 \mathrm{~m}$ ) sources added by nudging and a net instantaneous decay of $0.05 \mathrm{~d}^{-1}$. Results are plotted as in Fig. 13

\section{Copepodites}

Removing the adults from the picture allows quantification of the deep sources. We initialized a single population of MARMAP copepodites (C3 to $\mathrm{C} 5$ ) on January 1 and transported them in the vertically averaged flow with $4 \%$ net decay $\mathrm{d}^{-1}$. Results are illustrated in Fig. 14. The lack of persistence over the Jordan Basin is even more pronounced relative to the observations, and Wilkinson Basin also appears to be washing out too fast. From this and the previous simulation we deduce that there are significant numbers of copepodites below $200 \mathrm{~m}$ in the deep basins which are not accounted for in the data; that they are rising into the circulation during January and February; and that they are locally dominating the distribution pattern.

We added sources to this simulation by nudging toward the observed distribution where the depth exceeded $200 \mathrm{~m}$, with a time scale of $10 \mathrm{~d}^{7}$ The net decay rate was increased to $5 \% \mathrm{~d}^{-1}$ to offset the additional sources ( $1 \%$ mortality, $4 \%$ development). Results appear in Fig. 15. The nudging is successful in restoring the observed persistence. Additionally, the higher net decay is effective in reducing the overabundance south of Wilkinson Basin. In Fig. 16 we show the integrated source rates over the 2 mo. The unobserved abundances implied are comparable to those observed. Their rate of emergence is greatest in January, with the process tapering off in February.

This simulation supports a scenario of deep, immobile population centers of diapausing copepodites, entering the circulation during January and February, transported in the vertically averaged flow, and molting to adult at $4 \% \mathrm{~d}^{-1}$. The result is high retention of

\footnotetext{
${ }^{7}$ We used first-order nudging of the form $R=\kappa\left(C_{0}-C\right)$. The time-dependent target $C_{0}$ was linearly interpolated among the observations; nudging was cancelled if it implied a sink rather than a source
} 


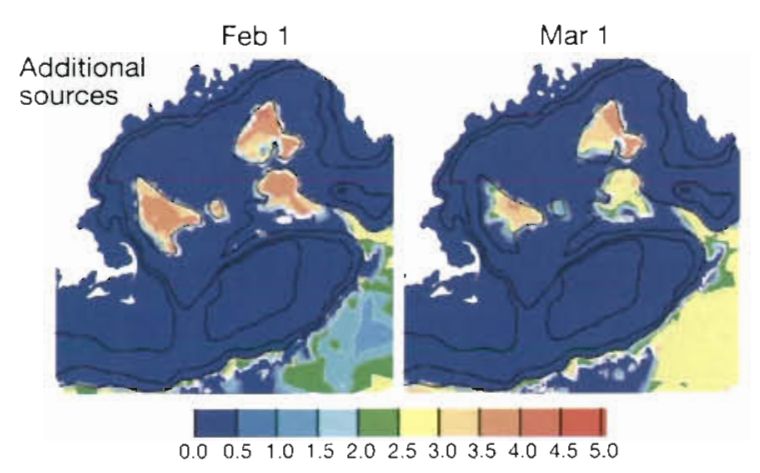

Fig. 16. Cumulative sources added by the nudging in Fig. 15. These are plotted as in Fig. 13 but here $A=$ the total number of animals added in the entire water column over the corresponding $30 \mathrm{~d}$ period

Gulf of Maine copepodites, with adult production sustained over the $60 \mathrm{~d}$ period and general southward transport toward Georges Bank and Great South Channel. Additional copepodites may be imported from the Scotian Shelf to Browns Bank, to Georges Bank south of the $100 \mathrm{~m}$ isobath, and to the northeast perimeter of the Gulf. Fidelity to the data would be improved by adding spatially variable mortality, notably in the shoal areas (e.g. the Northeast Peak of Georges Bank) where copepodite abundance appears too high.

\section{Adults}

Simulation of the adult stages requires initial conditions plus new production from the resting stock. The new production is taken from the previous simulation (C5s molting to adult at $4 \% \mathrm{~d}^{-1}$ ); initial conditions are taken from the January 1 MARMAP data. Both sources need to be sex-differentiated to properly capture the enhanced male mortality. New production was apportioned 1:1 according to the baseline population dynamics. Initial conditions were apportioned as $90 \%$ female, 10\% male. (Effectively we assumed that the differential mortality has been at work on these in situ animals.) All adults were transported in the surface layer with baseline mortality (Fig. 17).

Results appear in Fig. 18. The faster surface flow advects adults away from their relatively stationary copepodite sources, toward Georges Bank and Great South Channel. The empty inflows also penetrate further, diluting the Northeast Peak of the Bank and Georges Basin from the Scotian Shelf, and northern Wilkinson Basin from the Bay of Fundy area.

Relative to the data, this simulation overpopulates Georges Bank, Great South Channel, and Nantucket Shoals; and the Wilkinson Basin population center appears to have advected too far south. The need for

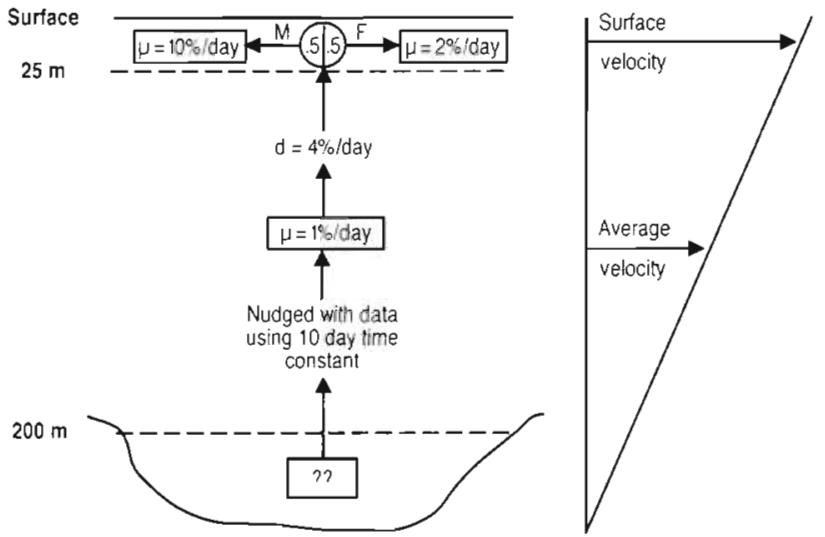

Fig. 17. Schematic of baseline 3 -layer $G_{0}$ simulation. The deep diapausing population is unknown $n_{i}$ its ascent into the flow is represented by the nudging as indicated

increased mortality in the shoal areas, suggested by the previous simulations, is even more apparent here. The overpopulation of Georges Bank would only be exacerbated if the Scotian Shelf inflows were nonempty, so this conclusion seems inescapable. Nonempty inflows from the Bay of Fundy could replenish the northern portion of Wilkinson Basin, counteracting the apparent southward shift of this aggregation.

Increasing baseline mortality by a factor of 5 where depth is $\leq 100 \mathrm{~m}$ is effective. Fig. 19 shows the results of this change. We accept this as a credible rendering of the $G_{0}$ dynamics:

- deep, immobile sources of copepodites, rising into the circulation throughout January and February;

- activating copepodites transported in the vertically averaged flow and molting to adult at $4 \% \mathrm{~d}^{-1}$;

- adults transported in the surface layer with baseline mortality;

- enhanced mortality for all $G_{0}$ stages in shoal areas.

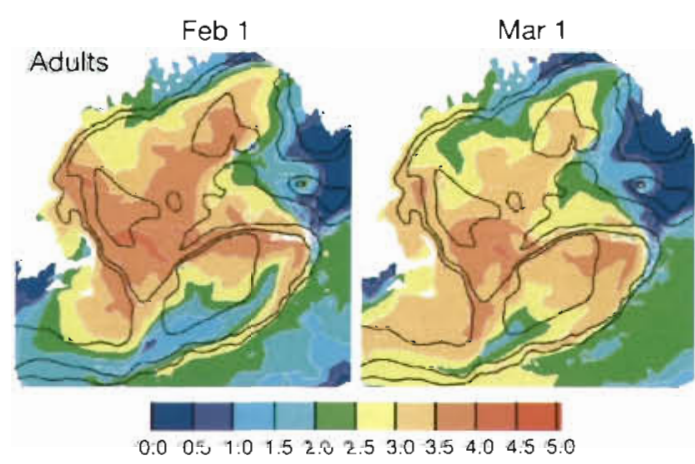

Fig. 18. Adult outcomes for the baseline 3-layer simulation. Adults are carried in the surface flow with patterns therefore affected by the surface convergence structure. They decay with the base model mortality and are increased by development from C5s. Results are plotted as in Fig. 13 but now $A=$ no. $\mathrm{m}^{-2}$ in the surface layer 

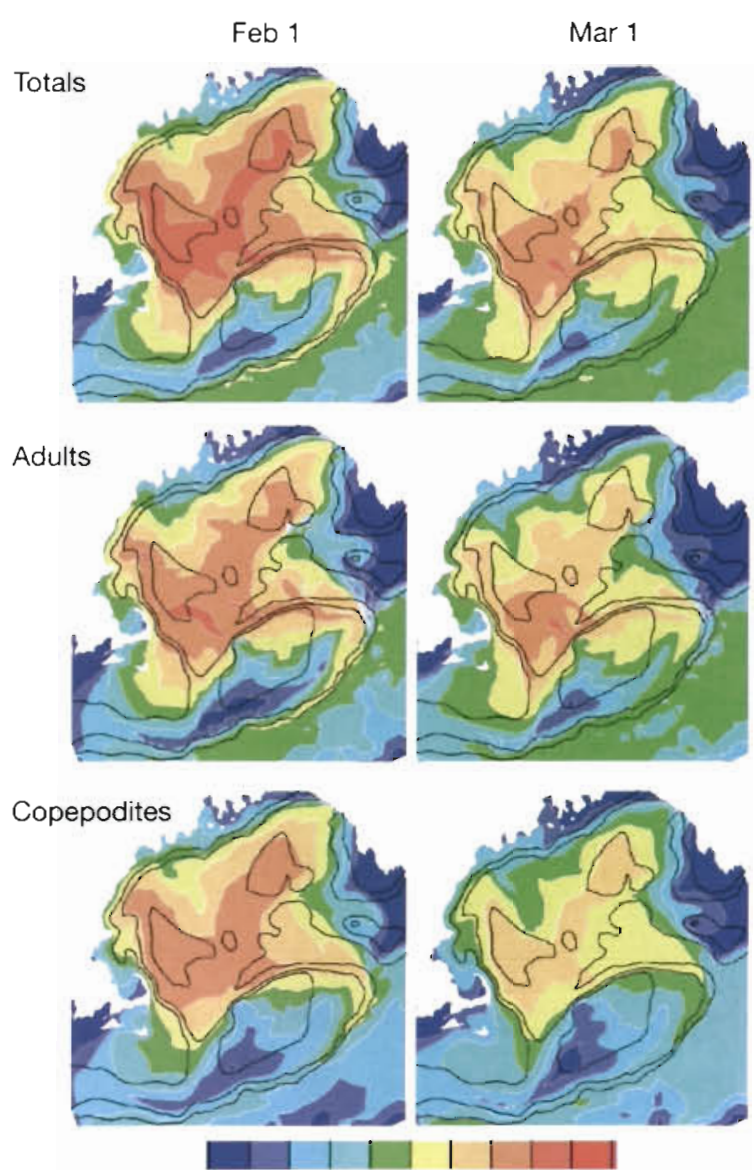

$\begin{array}{llllllllllll}0.0 & 0.5 & 1.0 & 1.5 & 2.0 & 2.5 & 3.0 & 3.5 & 4.0 & 4.5 & 5.0\end{array}$

Fig. 19. Final $G_{0}$ simulation. Copepodite sources in deep basins represented by nudging; baseline $\mu$ for all stages is increased 5 -fold in areas with $H \leq 100 \mathrm{~m}$. Results are plotted as in Fig. 13 with $A=$ no. $\mathrm{m}^{-2}$ in the appropriate fluid layer

\section{Initiation of generation 1}

Finally, we simulate the development of $G_{1}$ by enabling $G_{0}$ reproduction in the above model. The goal is to produce a realistic initiation of $G_{1}$ in space and time. The figure of merit is the emergence of $G_{1} \mathrm{C} 3 \mathrm{~s}$, which is not observed until April 1. Development rates from Table 1 used the climatological surface-layer temperature. As in Fig. 5, stages of duration greater than $1 \mathrm{~d}$ were subdivided to avoid developmental diffusion. Modeled $G$, females are not allowed to reproduce, thereby avoiding the distraction of a second generation.

\section{Baseline run}

In this case we initialize and simulate $G_{0}$ exactly as above, and enable reproduction. All $G_{1}$ stages are transported in the surface layer. Baseline population dynamics govern, with no food limitation.
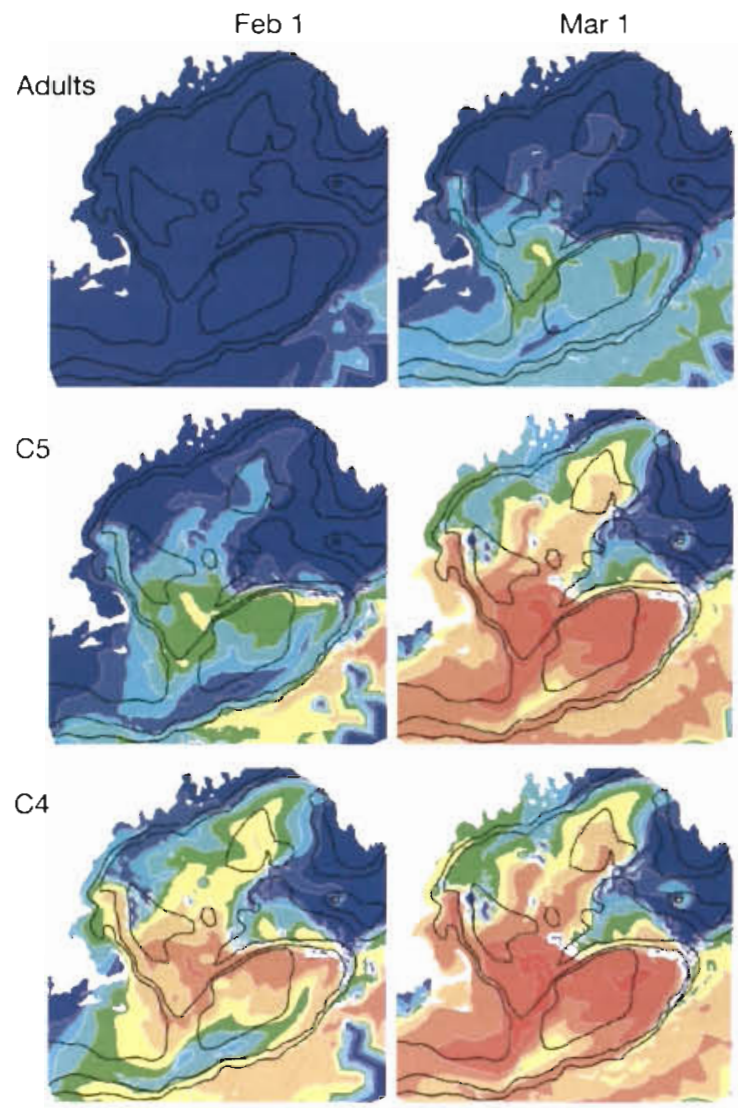

C3
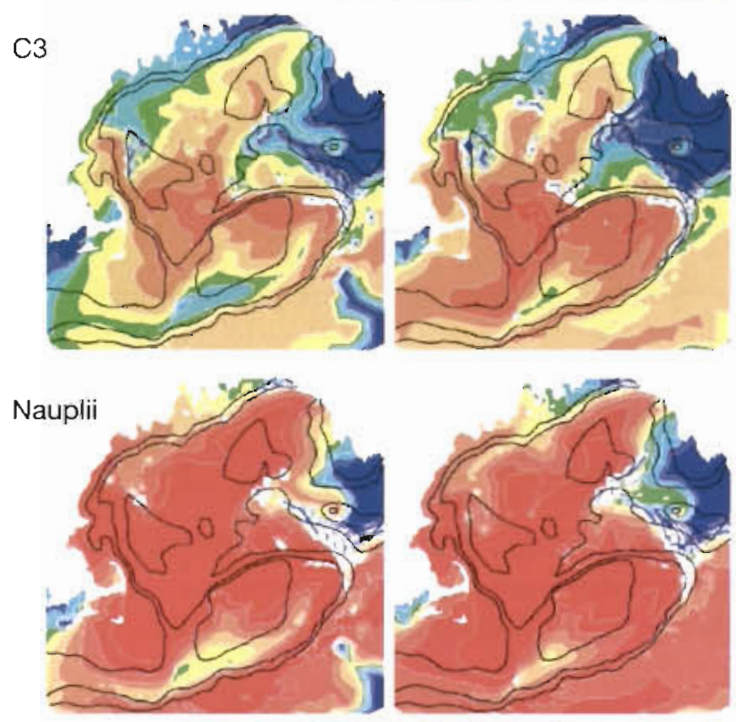

$0.0 \quad 0.5 \quad 1.0 \quad 1.5 \quad 2.02 .5 \quad 3.03 .5 \quad 4.04 .5 \quad 5.0$

Fig. 20. Baseline $G_{1}$ : no food effects. Base model population dynamics are active in this simulation. $G_{1}$ animals are carried in the surface layer and development rates are dependent upon the local climatological surface temperature. The result-

ing abundances for $G_{1}$ animals are plotted as in Fig. 18

The result is a premature bloom of $G_{1}$, illustrated in Fig. 20. By February 1, $G_{1}$ has already advanced beyond stage $\mathrm{C} 3$, backed up by a Gulf-wide distribution 
of nauplii. By March 1 we see that the modeled $G_{1}$ clearly dominates, and has reached the adult stages. This premature bloom is the simple result of baseline reproduction from $G_{0}$, which is assumed correct. It is exacerbated by the warmer climatology during January. ${ }^{8}$ Clearly the baseline population dynamics is not operative in the Gulf of Maine.

\section{Food limited run}

The most glaring need in the above results is to slow down the $G_{1}$ development. In this run we enabled linear food limitation as indicated in Table 1. Results appear in Fig. 21. The effect is clearly in the right direction, but the modeled $G_{1}$ is still ahead of observations. On February $1, G_{1}$ has begun to emerge at $C 3$ in significant numbers, and the naupliar abundance indicates a large, developing generation which emerges as copepodites by March 1 . Note also that this simulation is beginning to favor $G_{1}$ development on Georges Bank relative to the Gulf of Maine, consistent with the observed spatial patterns in chlorophyll and Calanus. The exception is southern Wilkinson Basin, where the data show a Calanus hole and we have a bloom in the simulation.

\section{Extreme food effect}

An extreme response to food limitation is shown in Fig. 22, where we simulated as in the baseline case but shut off viable egg production entirely when food $<150 \mu \mathrm{g} \mathrm{C}$ $\mathrm{I}^{-1}$. Essentially this makes $G_{0}$ sterile until it is transported onto Georges Bank. The results are provocative. The Gulf is devoid of $G_{1}$; on-bank, $G_{1}$ nauplii cover the central shoal on February 1 (note the chlorophyll pattern at this point in time), and much of the bank by March 1. Heaviest concentrations occur along the Northern. Flank, the point of entry, and appear to be advecting around to the Southern Flank. The anomalous bloom in southern Wilkinson Basin is removed.

We consider this simulation successful with respect to Georges Bank. Addition of upstream Calanus sources and a refined description of food effects would fill out the picture in the Gulf.

These simulations support the hypothesis that food imitation over the Gulf of Maine is fundamentally limiting the emergence of $G_{1}$. In this scenario, initiation of $G_{1}$ on Georges Bank is triggered by $G_{0}$ females arriving continuously in a food-poor surface-layer

${ }^{8}$ The Gulf reaches a midwinter temperature minimum in March
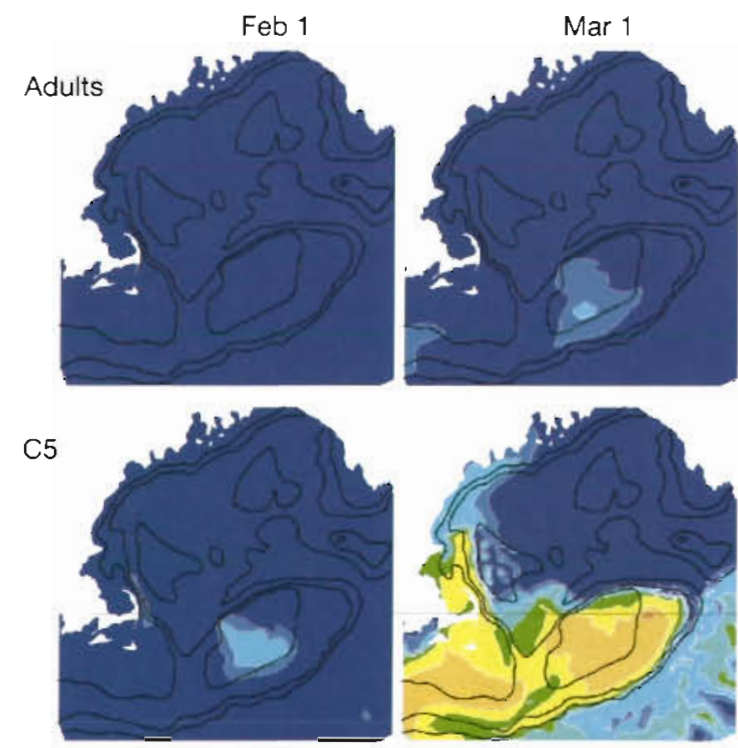

C4
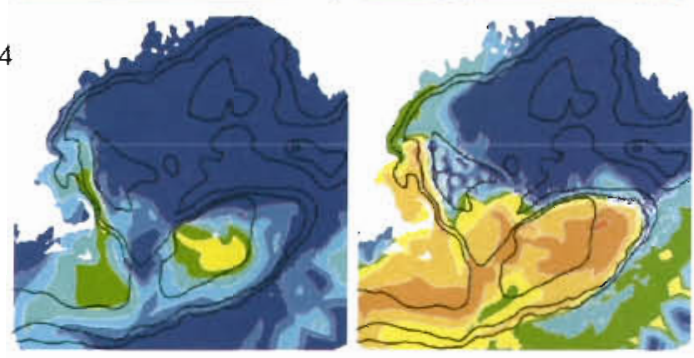

C3
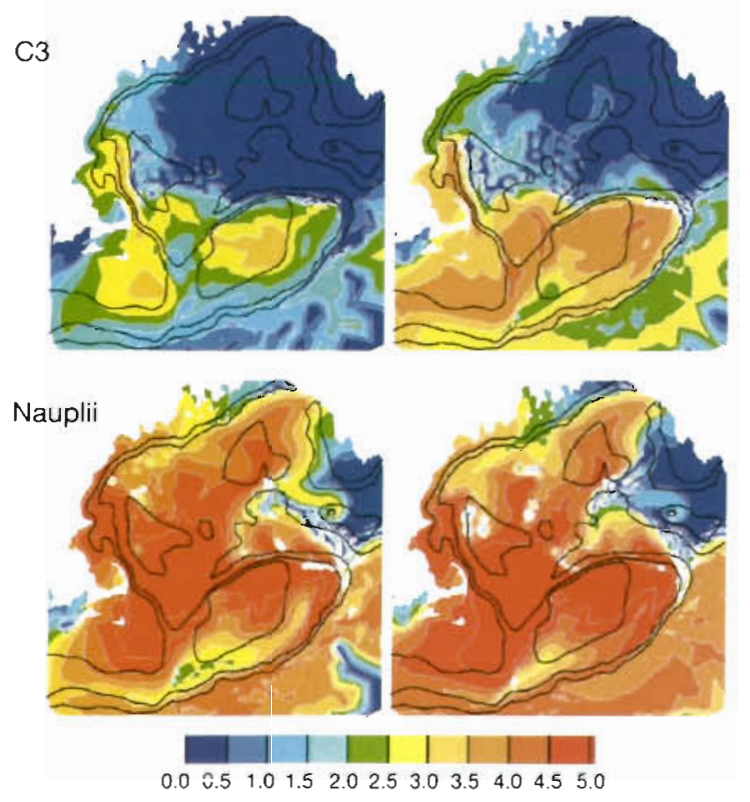

Fig. 21. Linear food Iimitation $G_{1}$ : baseline $G_{1}$ run with maximal development and egg production rates decreased linearly with food concentration below threshold values. Results are plotted as in Fig. 20

conveyor belt. The conveyor belt is sustained by deep reserves of copepodites being activated continuously during January through March. During this period the 

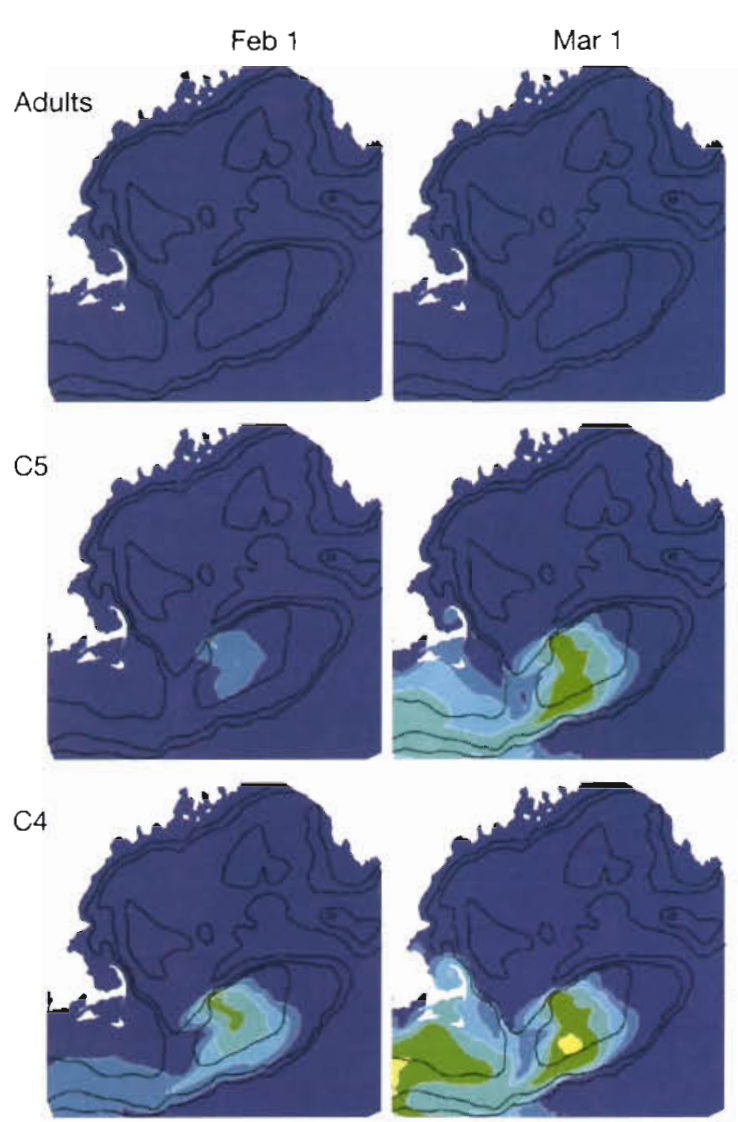

C3
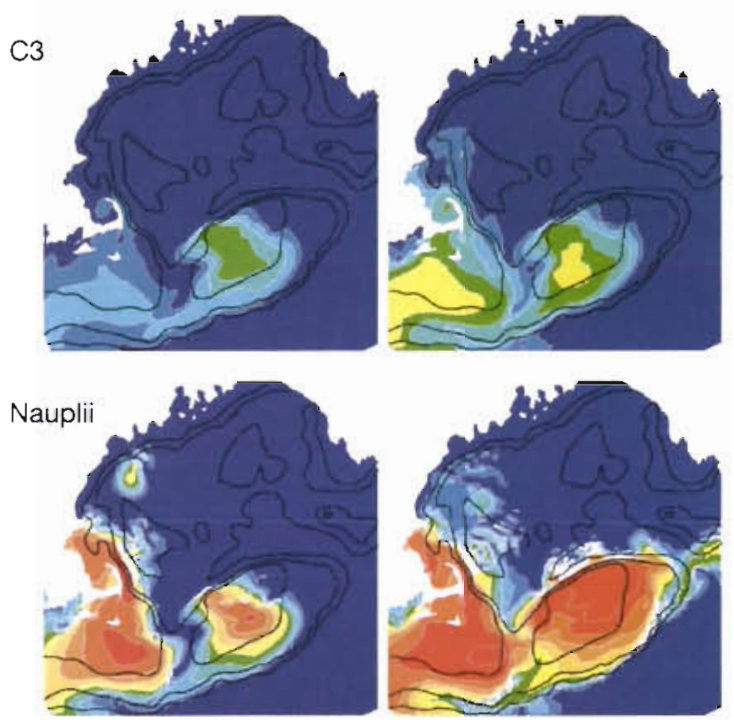

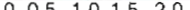

Fig. 22. Extreme food limitation $G_{1}$ : baseline $G_{1}$ run with no viable egg production below $150 \mathrm{mg} \mathrm{C \textrm {C } ^ { - 1 }}$. Results are plotted as in Fig. 20

phytoplankton bloom occurs on the Bank, elevating larger areas of the Bank above the assumed satiation threshold. Fig. 23 summarizes this final scenario.
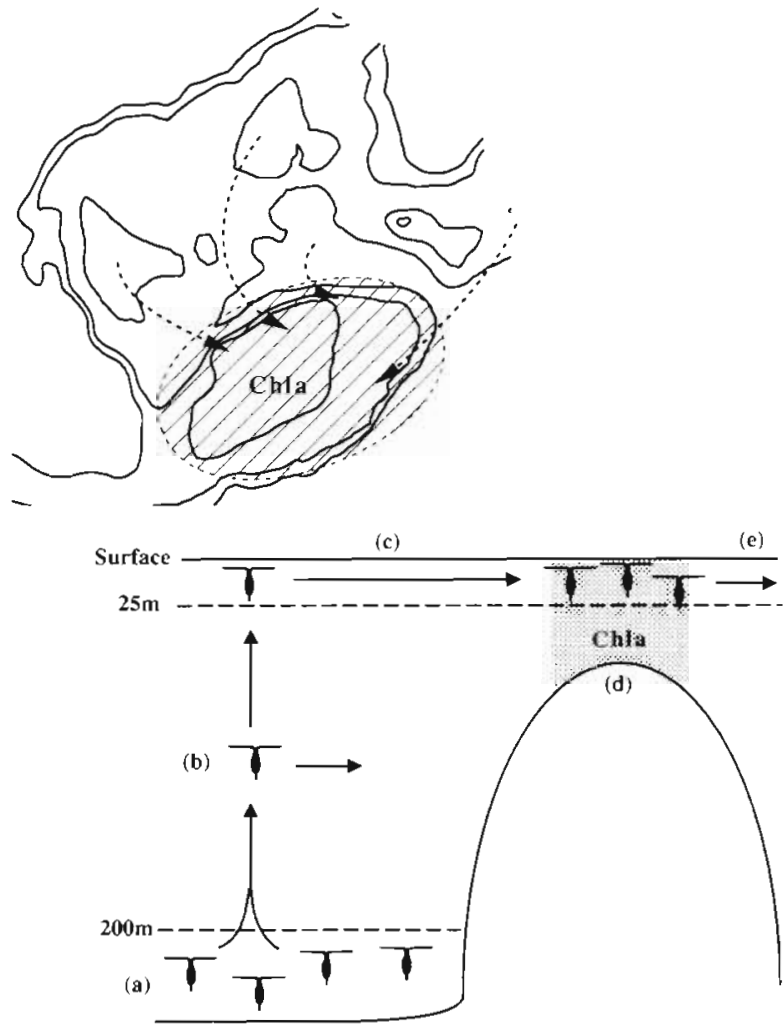

Fig. 23. Schematic of final $G_{1}$ initiation scenario. (a) Large source population of diapausing animals in the deep basins of the Gulf of Maine. (b) Slow bankward transport of rising C5s. (c) Fast bankward transport of adults in the surface layer. (d) Reproduction on the bank where food is abundant. (e) Loss from bank

\section{CONCLUSION}

We began this study with high-quality information about Calanus life history, its abundance and distribution in the Gulf of Maine, and the circulation. We have assembled a quantitative, Gulf-wide description linking these in a simulation model. The underlying premise has been that mean abundance and distribution is the result of basic animal characteristics combined with the climatological mean physical and biological environment. We generally confirm this premise: reasonable agreement between model and observation is obtained with sparse, credible parameterizations of real phenomena. There are many pitfalls in the sweeping simplifications necessary in a first modeling study, but several conclusions seem inescapable.

The passive tracers highlight features of the circulation alone:

- The deep basins of the Gulf are capable of populating most of Georges Bank; each has its own distinctive space-time signature.

- Inflow from the Scotian Shelf contributes to the Southern Flank and to the eastern Gulf of Maine. 
- Behaviour is a key ingredient in the transport. Populations aggregating in the surface layer move at roughly twice the speed of those with no depth preference and cross isobaths onto Georges Bank more readily.

- Convergence (downwelling) in the surface layer creates a distinctive pattern of transport 'lanes' to the Bank, and 'hot spots' of surface-layer aggregations, notably over the northeast peak and in the Great South Channel.

These passive features are the manifestation of fundamental constraints on all of the coupled physical biological outcomes. It is important to accept them as natural tendencies of the system.

The $G_{0}$ simulations are inspired by the observations, wherein during fall and early winter we see a diapausing population emerging to adulthood. The main conclusions are:

- A 3-layer description captures the big picture, with a deep immobile reservoir of diapausing copepodites; an intermediate layer of copepodites exiting diapause and transported in the vertically averaged flow; and a surface layer of newly molted adults.

- Enhanced mortality within the $100 \mathrm{~m}$ isobath is needed. Otherwise, advection delivers more animals to the bank and other shallow areas than are observed.

- Persistence of the C5 stock over the deep basins requires a significant flux from the deep reservoir. This aggregation has not been sampled; therefore existing inventories underestimate the abundance over the deep basins. The unmeasured population appears to be comparable to that measured.

- Exit from diapause is a prolonged process, lasting for roughly $2 \mathrm{mo}$. The source regions in the Gulf provide a persistent, rather than an impulsive, loading of $G_{0}$ adults to Georges Bank.

These $G_{0}$ dynamics may be deduced irrespective of the details of reproduction and development; only a complete inability to model $G_{1}$ would cause a retreat from these conclusions.

Activation of $G_{0}$ reproduction provides additional insight concerning $G_{1}$ dynamics:

- There is an undeniable need to delay the development of $G_{1}$. Unchecked, the $G_{0}$ females produce a premature bloom relative to the observed $\mathrm{C} 3$ breakthrough.

- The space-time pattern of chl $a$ is a reasonable proxy for the pattern of $G_{1}$ inhibition needed, suggesting food limitation on $G_{1}$ initiation.

- 'Gentle' chlorophyll-based reduction of spawning and development (i.e. linear decrease below baseline thresholds) is effective in delaying the bloom but it is not sufficient. Notable is the failure to capture the observed low abundance in southern Wilkinson Basin
- Severe reduction in viable egg production over the Gulf provides a reasonable explanation for the timing of $G_{1}$ initiation, and is consistent with observations

The $G_{1}$ initiation scenario may thus be summarized as follows. A conveyor belt in the surface layer delivers $G_{0}$ females to Georges Bank, sustained over time by deep-basin sources. Over the Gulf, viable reproduction is severely inhibited due to low food concentration. Entry into the primary production zone on the Bank triggers the initiation of $G_{1}$ there. Secondary production is thus an on-bank process, sustained by fecund females arriving on a food-limited conveyor belt.

We conclude our study here. The model results quantify a credible scenario for the initiation of the spring Calanus bloom. Georges Bank is covered with nauplii which will, broadly speaking, emerge in the MARMAP data as late-stage copepodites at the right time and place.

Further refinements to the model are clearly called for. Continuation of these simulations through $G_{1}$ and $G_{2}$ should involve a fully 3 -dimensional treatment to properly represent the Georges Bank frontal regime. A more refined ecological description of the bloom is also needed, including a detailed description of the predator assemblage and primary production. And, it would be very valuable to add some of the features of individual-based models (as demonstrated by Miller et al. 1998) to represent individual life history and variability.

Large additional computational demands are implied. These could be mitigated by focusing on a limited-area Bank simulation-our results provide a distinctive and simple conceptual model of the GulfBank coupling. The growth in complexity, however, is the limiting modeling issue. It is unlikely that sufficient data for such a full-featured simulation could be obtained. Formal inversion methods for the biological portions of the model could be quite productive in this context (see e.g. McGillicuddy et al. 1998). The complexity reduction methods of Flierl \& Davis (1997) will also be important and may be facilitated by the relatively simple form of the Gulf-Bank coupling found herein.

Finally, our study highlights the need for more data in key areas. The existing abundance and distribution data, while pathbreaking in its scope, nevertheless leaves several key aspects to inference:

- near-bottom abundance in the deep basins of the Gulf-herein these are significant population centers;

- vertical positioning of the various stages - critical in determining the operative transport regime;

- abundance and distribution of the nauplii and early copepodites - the key to understanding reproduction and the trophic link to e.g. larval fish; 
- abundance and distribution of all stages on the Scotian Shelf-herein this source is a critical unknown which advects into the system in key areas. In terms of vital rates, the limiting effects of food scarcity, especially on fertility and development of $G_{0}$ over the Gulf of Maine, are a key inference in the present study. This has limited experimental support and deserves close scrutiny. Related is the need for closer scrutiny of primary production dynamics. Spatial and temporal variations in chlorophyll concentration on the Bank are comparable to uncertainties in the physiological response to food availability. Therefore the issue of timing in the arrival of adult females with respect to the spring phytoplankton bloom remains unresolved by our analysis. Lastly, the details of the predatory environment on Georges Bank are likely, ultimately, to reveal many important interactions and deserve continued experimental attention.

Acknowledgements. We thank Ken Sherman, Jack Jossi, and Jack Greene for providing us access to the MARMAP zooplankton data base. Carol Meise was instrumental in processing this data and also provided many helpful discussions. Jay O'Reilly provided the processed chlorophyll data. Bob Campbell provided the Calanus stage durations. Ted Durbin, Charlie Miller, and Jeff Runge have contributed numerous insights to our discussions over the course of this work. We are grateful to all for their interest and help. This is Contribution number 98 of the U.S. GLOBEC program, sponsored jointly by NSF and NOAA. This is WHOI contribution number 9689

\section{LITERATURE CITED}

Aksnes DL, Blindheim J (1996) Circulation patterns in the North Atlantic and possible impact on population dynamics of Calanus finmarchicus. Ophelia 77:7-28

Belehradek J (1935) Temperature and living matter. Protoplasma Monogr 8:1-277

Bigelow HB (1926) Plankton of the offshore waters of the Gulf of Maine. Bull US Bur Fish 40:1-509

Bigelow HB (1927) Physical oceanography of the Gulf of Maine. Bull US Bur Fish 40:511-1027

Brooks DA (1985) The vernal circulation in the Gulf of Maine. J Geophys Res 90(C5):4687-4705

Brown WS, Irish JD (1992) The annual evolution of geostrophic flow in the Gulf of Maine: 1986-1987. J Phys Oceanogr 22:445-473

Carlotti F, Radach G (1996) Seasonal dynamics of phytoplankton and Calanus finmarchicus in the North Sea as revealed by a coupled one-dimensional model. Limnol Oceanogr 41(3):522-539

Chen C (1992) Variability of currents in Great South Channel and over Georges Bank: observation and modeling. PhD thesis, Woods Hole Oceanographic Institution, Woods Hole, MA

Clarke GL, Pierce EL, Bumpus DF (1943) The distribution and reproduction of Sagitta elegans on Georges Bank in relation to hydrographic conditions. Biol Bull 85:201-226

Davis CS (1984a) Predatory control of copepod seasonal cycles on Georges Bank. Mar Biol 82:31-40

Davis CS (1984b) Interaction of a copepod population with the mean circulation on Georges Bank. J Mar Res 42:573-590

Davis CS (1984c) Food concentrations on Georges Bank: nonlimiting effect on development and survival of laboratory reared Pseudocalanus sp. and Paracalanus parvus (Copepoda: Calanoida). Mar Biol 82:41-46

Davis CS (1987) Zooplankton life cycles. In: Backus RH Bourne DW (eds) Georges Bank. MIT Press, Cambridge, p 256-267

Davis CS (1991) Georges Bank holozooplankton. In: GLOBEC: Northwest Atlantic Program. US GLOBEC report no. 2, Joint Oceanographic Institution, Washington, DC, $p 48-50$

Dortch MS, Chapman RS, Abt SR (1992) Application of threedimensional Lagrangian residual transport. J Hydr Eng 118:831-848

Durbin EG, Gilman SL, Campbell RG, Durbin AG (1995) Abundance, biomass, vertical migration and estimated development rate of the copepod Calanus finmarchicus in the southern Gulf of Maine during late spring. Cont Shelf Res 15(4/5):571-591

Flagg CN (1987) Hydrographic structure and variability. In: Backus RH, Bourne DW (eds) Georges Bank. MIT Press, Cambridge, p 108-124

Flierl GR, Davis CS (1997) Reduction of complexity in biological/physical models. J Mar Res (in press)

Franks PJS (1992) Sink or swim: accumulation of biomass at fronts. Mar Ecol Prog Ser 82:1-12

Franks PJS, Chen C (1996) Plankton production in tidal fronts: a model of Georges Bank in summer J Mar Res 54: $631-651$

GLOBEC (1991) Northwest Atlantic Program. US GLOBEC report no. 2, Joint Oceanographic Institution, Washington, DC

GLOBEC (1992) Northwest Atlantic Implementation Plan. US GLOBEC report no. 6, University of California, Davis

Greenberg DA (1990) The contribution of modeling to understanding the dynamics of the Bay of Fundy and the Gulf of Maine. In: Davies AM (ed) Modeling marine systems 2. CRC Press, Boca Raton, FL, p $107-140$

Hannah CG, Naimie CE, Loder JW, Werner FE (1998) Upper ocean transport mechanisms from the Gulf of Maine to Georges Bank, with implications for Calanus supply. Cont Shelf Res 17, 15:1887-1911

Herman AW, Sameoto DD, Shunnian C, Mitchell MR, Petrie B, Cochrane N (1991) Sources of zooplankton on the Nova Scotia shelf and their aggregations within deep-shelf basins. Cont Shelf Res 11(3):211-238

Hirche HJ (1987) Temperature and plankton: II. Effect on respiration and swimming activity in copepods from the Greenland Sea. Mar Biol 94:347-356

Hirche HJ (1990) Egg production of Calanus finmarchicus at low temperature. Mar Biol 106:53-58

Hirche HJ (1996a) The reproductive biology of the marine copepod, Calanus finmarchicus-a review. Ophelia 44: $111-128$

Hirche HJ (1996b) Diapause in the marine copepod, Calanus finmarchicus-a review. Ophelia 44:129-144

Hirche HJ, Kwasniewski S (1997) Distribution, reproduction and development of Calanus species in the Northeast Water in relation to environmental conditions. J Mar Sys 10:299-317

Hirche HJ, Meyer U, Niehoff B (1997) Egg production of Calanus finmarchicus: effect of temperature, food, and season. Mar Biol 127:609-620

Horne EPW, Loder JW, Naimie CE, Oakey NS (1996) Turbulence dissipation rates and nitrate supply in the upper water column on Georges Bank. Deep Sea Res Part II Top Stud Oceanogr 43(7-8):1683-1712 
Kenney RD, Wishner KF (1995) The South Channel Ocean Productivity Experiment. Cont Shelf Res 15(4/5):373-384

Klein P (1987) A simulation of some physical and biologic interactions. In: Backus RH, Bourne DW (eds) Georges Bank. MIT Press, Cambridge, p 395-402

Kleppel GS, Davis CS, Carter K (1996) Temperature and copepod growth in the sea: a comment on the temperature dependent model of Huntley and Lopez. Am Nat 148(2): $397-406$

Laabir M, Poulet SA, Ianora A, Miralto A, Cueff A (1995) Reproductive response of Calanus helgolandicus. II. In situ inhibition of embryonic development. Mar Ecol Prog Ser 129:97-105

Lewis CV (1997) Biological-physical interactions on Georges Bank: plankton transport and population dynamics of the ocean quahog, Arctica islandica. PhD thesis, Woods Hole Oceanographic Institution and Massachusetts Institute of Technology

Lewis CV, Davis C, Gawarkiewicz G (1994) Wind-forced biological-physical interactions on an isolated off-shore bank Deep Sea Res Part II Top Stud Oceanogr 41(1):51-73

Lough RG, Smith WG, Werner FE, Loder JW, Page FH, Hannah CG, Naimie CE, Perry RI, Sinclair MM, Lynch DR (1994) The influence of wind-driven advection on the interannual variability in cod egg and larval distributions on Georges Bank: 1982 vs 1985. ICES Mar Sci Symp 198 $356-378$

Lynch DR, Ip JTC, Naimie CE, Werner FE (1995) Convergence studies of tidally rectified circulation on Georges Bank. Quantitative skill assessment for coastal ocean models. In: Lynch DR, Davies AM (eds) Coastal and Estuarine Studies, Vol 47. American Geophysical Union, Washington, DC, p 153-174

Lynch DR, Ip JTC, Naimie CE, Werner FE (1996) Comprehensive coastal circulation model with application to the Gulf of Maine. Cont Shelf Res 16:875-906

Lynch DR, Holboke MJ, Naimie CE (1997) The Maine Coastal Current: spring climatological circulation. Cont Shelf Res $17(6): 605-634$

Madin LP, Bollens SM, Horgan E, Butler M, Runge J, Sulivan BK, Klein-MacPhee G, Durbin E, Durbin AG, Van Keuren D, Plourde S, Bucklin A, Clarke ME (1996) Voracious planktonic hydroids: unexpected predatory impact on a coastal ecosystem. Deep Sea Res Part II Top Stud Oceanogr 43(7-8):1823-1830

Marshall SM, Orr AP (1955) The biology of a marine copepod, Calanus finmarchicus (Gunnerus). Oliver \& Boyd, Edinburgh

McGillicuddy DJ, Lynch DR, Moore AM, Gentleman WC, Davis CS, Meise CJ (1998) An adjoint data assimilation approach to the estimation of Pseudocalanus spp. population dynamics. Fish Oceanogr

Meise CJ, O'Reilly JE (1996) Spatial and seasonal patterns in abundance and age-composition of Calanus finmarchicus in the Gulf of Maine and on Georges Bank: 1977-1987. Deep Sea Res Part II Top Stud Oceanogr 43 $(7-8): 1473-1501$

Editorial responsibility: Kenneth Sherman (Contributing Editor), Narragansett, Rhode Island, USA
Miller CB, Lynch DR, Carlotti F, Gentleman W. Lewis C (1998) Coupling of an individual-based population dynamical model for stocks of Calanus finmarchicus with a circulation model for the Georges Bank region. Fish Oceanogr

Mullin MM (1963) Comparative ecology of the genus Calanus in the Gulf of Maine. PhD thesis, Department of Biology, Harvard University

Naimie CE (1995) On the modeling of the seasonal variation of the three-dimensional circulation near Georges Bank. $\mathrm{PhD}$ thesis, Dartmouth College, Hanover, NH

Naimie CE, Loder JW, Lynch DR (1994) Seasonal variation of the 3-D residual circulation on Georges Bank. J Geophys Res 99(C8):15967-15989

Niehoff B, Hirche HJ (1996) Oogenesis and gonad maturation in the copepod Calanus finmarchicus and the prediction of egg production from preserved samples. Polar Biol 16: $601-612$

Olson DB, Backus RH (1985) The concentrating of organisms at fronts: a cold-water fish and a warm-core Gulf Stream ring. J Mar Res 43:113-137

O'Reilly JE, Zetlin C (1997) Monongraph on the seasonal, horizontal, and vertical distributions of phytoplankton chlorophyll $a$ in the Northeast U.S. Continental Shelf Ecosystem. NOAA Tech Rep NMFS (in press)

Plourde S, Runge JA (1993) Reproduction of the planktonic copepod Calanus finmarchicus in the lower St. Lawrence estuary: relation to the cycle of phytoplankton production and evidence for a Calanus pump. Mar Ecol Prog Ser 102: 217-227

Runge JA, Plourde S (1996) Fecundity characteristics of Calanus finmarchicus in coastal waters of Eastern Canada. Ophelia 44:171-187

Sameoto DD, Herman AW (1990) Life cycle and distribution of Calanus finmarchicus in deep basins on the Nova Scotia shelf and seasonal changes in Calanus spp. Mar Ecol Prog Ser 66:225-237

Sherman K, Grosslein M, Mountain D, Busch D, O'Reilly J, Theroux R (1996) The Northeast Shelf ecosystem: an initial perspective; In: Sherman K, Jaworski NA, Smayda TJ (eds) The Northeast Shelf ecosystem: assessment, sustainability, and management. Blackwell Science, Cambridge, p 103-126

Sullivan BK, Meise CJ (1996) Invertebrate predators of zooplankton on Georges Bank, 1977-1987. Deep Sea Res Part II Top Stud Oceanogr 43(7-8): 1503-1520

Uye SI (1996) Induction of reproductive failure in the planktonic copepod Calanus pacificus by diatoms. Mar Ecol Prog Ser 133:89-97

Werner FE, Page FH, Lynch DR, Loder JW, Lough RG, Perry RI, Greenberg DA, Sinclair MM (1993) Influences of mean advection and simple behavior on the distribution of cod and haddock early life stages on Georges Bank. Fish Oceanogr 2(2):43-64

Wiebe PH, Beardsley RC, Mountain DG, Bucklin A (1996) Global Ocean Ecosystem Dynamics-initial program in Northwest Atlantic. Sea Technol 37:867-876

Submitted: January 14, 1998; Accepted: May 13, 1998

Proofs received from author(s): July 14, 1998 